\title{
Continuous Estimate of Atlantic Oceanic Freshwater Flux at $26.5^{\circ} \mathrm{N}$
}

\author{
Elaine L. McDonagh, ${ }^{*}$ Brian A. King, ${ }^{*}$ Harry L. Bryden, ${ }^{+}$PegGy Courtois, ${ }^{+}$ \\ ZOLTAN SZUTS,,$* *$ MOLlY BARINGER, ${ }^{@}$ STUART A. CUNNINGHAM,, \\ CHRIS ATKINSON, ${ }^{+,++}$AND GERARD MCCARTHY* \\ * National Oceanography Centre, University of Southampton, Waterfront Campus, Southampton, United Kingdom \\ ${ }^{+}$Ocean and Earth Science, National Oceanography Centre, University of Southampton, Empress Dock, \\ Southampton, United Kingdom \\ \# Max Planck Institute for Meteorology, Hamburg, Germany \\ ${ }^{\circledR}$ Physical Oceanography Division, NOAA/Atlantic Oceanographic and Meteorological Laboratory, Miami, Florida \\ ${ }^{\&}$ Scottish Association of Marine Science, Scottish Marine Institute, Oban, United Kingdom
}

(Manuscript received 18 July 2014, in final form 5 August 2015)

\begin{abstract}
The first continuous estimates of freshwater flux across $26.5^{\circ} \mathrm{N}$ are calculated using observations from the RAPID-MOCHA-Western Boundary Time Series (WBTS) and Argo floats every 10 days between April 2004 and October 2012. The mean plus or minus the standard deviation of the freshwater flux $\left(F_{W}\right)$ is $-1.17 \pm$ $0.20 \mathrm{~Sv}\left(1 \mathrm{~Sv} \equiv 10^{6} \mathrm{~m}^{3} \mathrm{~s}^{-1}\right.$; negative flux is southward), implying a freshwater divergence of $-0.37 \pm 0.20 \mathrm{~Sv}$ between the Bering Strait and $26.5^{\circ} \mathrm{N}$. This is in the sense of an input of $0.37 \mathrm{~Sv}$ of freshwater into the ocean, consistent with a region where precipitation dominates over evaporation. The sign and the variability of the freshwater divergence are dominated by the overturning component $(-0.78 \pm 0.21 \mathrm{~Sv})$. The horizontal component of the freshwater divergence is smaller, associated with little variability and positive $(0.35 \pm$ $0.04 \mathrm{~Sv})$. A linear relationship, describing $91 \%$ of the variance, exists between the strength of the meridional overturning circulation (MOC) and the freshwater flux $\left(-0.37-0.047 \mathrm{~Sv}\right.$ of $F_{W}$ per Sverdrups of MOC). The time series of the residual to this relationship shows a small $(0.02 \mathrm{~Sv}$ in $8.5 \mathrm{yr})$ but detectable decrease in the freshwater flux (i.e., an increase in the southward freshwater flux) for a given MOC strength. Historical analyses of observations at $24.5^{\circ} \mathrm{N}$ are consistent with a more negative freshwater divergence from -0.03 to $-0.37 \mathrm{~Sv}$ since 1974 . This change is associated with an increased southward freshwater flux at this latitude due to an increase in the Florida Straits salinity (and therefore the northward salinity flux).
\end{abstract}

\section{Introduction}

The climate of northwest Europe and indeed the whole of the Northern Hemisphere is profoundly influenced by the oceanic transport of heat and salt from the tropics to the subpolar regions. The release of heat by the oceans from middle-to-high latitudes in the Atlantic makes a major contribution to the relatively mild climate in

\footnotetext{
** Current affiliation: Applied Physics Laboratory, University of Washington, Seattle, Washington.

${ }^{++}$Current affiliation: Met Office Hadley Centre, Exeter, Devon, United Kingdom.

Corresponding author address: Elaine McDonagh, National Oceanography Centre, University of Southampton, Waterfront Campus, European Way, Southampton SO14 3ZH, United Kingdom.

E-mail: e.mcdonagh@noc.ac.uk
}

northwest Europe, which is up to $6^{\circ} \mathrm{C}$ warmer than similar maritime climates bordering the Pacific (Feulner et al. 2013). The oceanic heat transport reaches a maximum of about $1.3 \mathrm{PW}$ near $25^{\circ} \mathrm{N}$ where its strength and variability are largely set by the meridional overturning circulation (MOC; Johns et al. 2011). The MOC at $26.5^{\circ} \mathrm{N}$ in the Atlantic consists of a surface northward flow of warm water concentrated in the Florida Straits and a cold, southward deep water return flow formed primarily by cooling in the subpolar regions. The salinity of the upper North Atlantic, driven by oceanic freshwater fluxes into the basin and the balance of freshwater input to the ocean (e.g., from the atmosphere by evaporation vs precipitation, river runoff, and ice melt), controls the quantity, or even existence, of this deep-water formation (Marsh et al. 2007). Changes in the freshwater input have been observed; for example, the hydrological cycle is thought to have intensified in recent decades and Arctic 


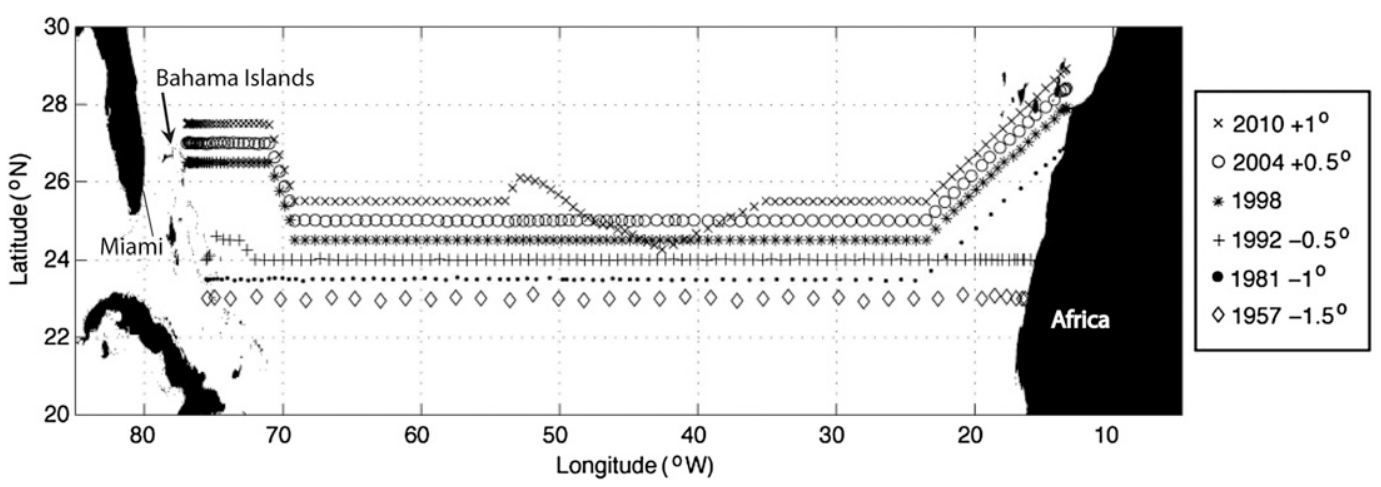

FIG. 1. Position of CTD stations occupied in the interior for all six hydrographic repeat sections of the $24.5^{\circ} \mathrm{N}$ section. Note that the sections are offset meridionally for clarity. Reproduced from Atkinson et al. (2012).

ice is melting (Rhein et al. 2013). However, we have little information on variability of oceanic freshwater fluxes, a potential factor in the future strength of the MOC.

Previous estimates of the North Atlantic oceanic freshwater flux have used data from six repeat hydrographic sections at $24.5^{\circ} \mathrm{N}$ (Fig. 1). The first, made using 1957 data (Hall and Bryden 1982), estimated a freshwater input (in the sense of precipitation exceeding evaporation) of $0.03 \mathrm{~Sv}\left(1 \mathrm{~Sv} \equiv 10^{6} \mathrm{~m}^{3} \mathrm{~s}^{-1}\right)$ between $24.5^{\circ} \mathrm{N}$ and the Bering Strait. Freshwater input estimates based on the 1981 data (Talley 2008; Dobroliubov 1997; as reported by Wijffels 2001) are much larger $(0.28$ and $0.44 \mathrm{~Sv}$, respectively). Finally, estimates based on the 1990s data (Dobroliubov 1997; as reported by Wijffels 2001; Lavin et al. 2003) are 0.53 and $0.5 \mathrm{~Sv}$, respectively. These analyses suggest that the freshwater input between the Bering Strait and $24.5^{\circ} \mathrm{N}$ is increasing. The size of the change $(\sim 0.5 \mathrm{~Sv})$ is significant, equivalent in magnitude to the net evaporation over the North Atlantic subtropical gyre (Wijffels 2001; Schanze et al. 2010). Here we construct and examine a time series of oceanic freshwater flux, decomposing this into components to determine the relative importance of the circulation strength and the salinity field on variability in the freshwater fluxes.

At $26.5^{\circ} \mathrm{N}$ in the Atlantic, data from the RAPIDMOCHA-Western Boundary Time Series (WBTS) (McCarthy et al. 2015; hereafter the RAPID array) offer the opportunity to calculate a time series of salinity fluxes and therefore freshwater fluxes-this has never been done before. In section 2 the data used in this calculation are outlined. The calculation of salinity and freshwater flux time series are detailed in section 3. Freshwater divergence and its components are calculated in section 4 . Section 5 contains a summary of the uncertainty analysis that is detailed in the appendix. In section 6 the historical estimates of the freshwater divergence are examined and put into the context of the variability of the time series. Section 7 contains the summary and conclusions.

\section{Data}

The principal datasets combined in this calculation are as follows:

(i) Data used in the MOC calculation at $26.5^{\circ} \mathrm{N}$ (Smeed et al. 2014). This includes salinity observations and transport estimates calculated from the U.K.-U.S. $26.5^{\circ} \mathrm{N}$ RAPID array (Fig. 2; McCarthy et al. 2015), Ekman transport calculated from ERAInterim winds (Dee et al. 2011), and submarinecable-based estimates of transport through the Florida Straits at $27^{\circ} \mathrm{N}$ (Baringer and Larsen 2001).

(ii) Salinity distribution and circulation structure away from the locations of the moorings (upper interior in Fig. 2), from an optimal interpolation (OI) product (B. King and E. McDonagh 2015, unpublished manuscript). The OI produces gridded fields of temperature and salinity on a $0.25^{\circ}$ longitude grid at $26.5^{\circ} \mathrm{N}$ down to $2000 \mathrm{dbar}\left(1 \mathrm{dbar}=10^{4} \mathrm{~Pa}\right)$ every 10 days. Mapping of anomalies relative to Hydrobase2 (Curry 2002) is done on density surfaces, recombined with Hydrobase2 climatology and interpolated back onto pressure levels to generate the timevariable gridded fields. We use a horizontal (on density surfaces), isotropic, decorrelation length scale of $500 \mathrm{~km}$. The input data for the OI mapping are all Argo temperature and salinity data that had passed the Argo quality control with a flag of 1 (good data) up to the date of Argo data download (27 August 2013) and gridded mooring temperature and salinity data from the moorings in the upper interior (Fig. 2).

(iii) Six transatlantic hydrographic repeat sections at $24.5^{\circ} \mathrm{N}$ that indicate the structure of the salinity flux across the section informing what assumptions can reasonably be made and further informing the calculation of uncertainties (section 5 and appendix). The locations of these repeats are shown in Fig. 1 and potential temperature and salinity sections from the 
a) $24 \mathrm{~N} 2010$ (Di346) - Potential temperature

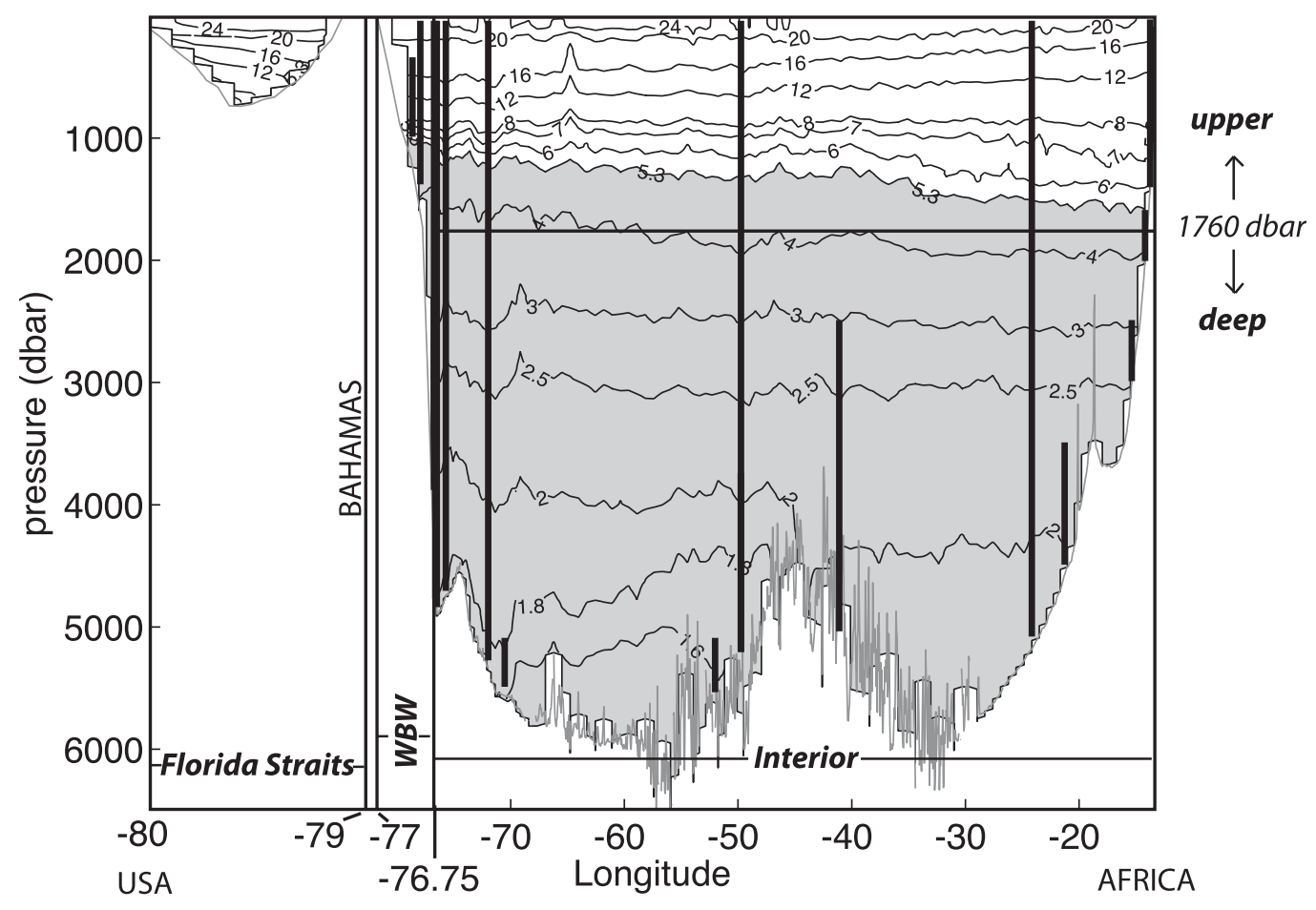

b) $24 \mathrm{~N} 2010$ (Di346) - Salinity

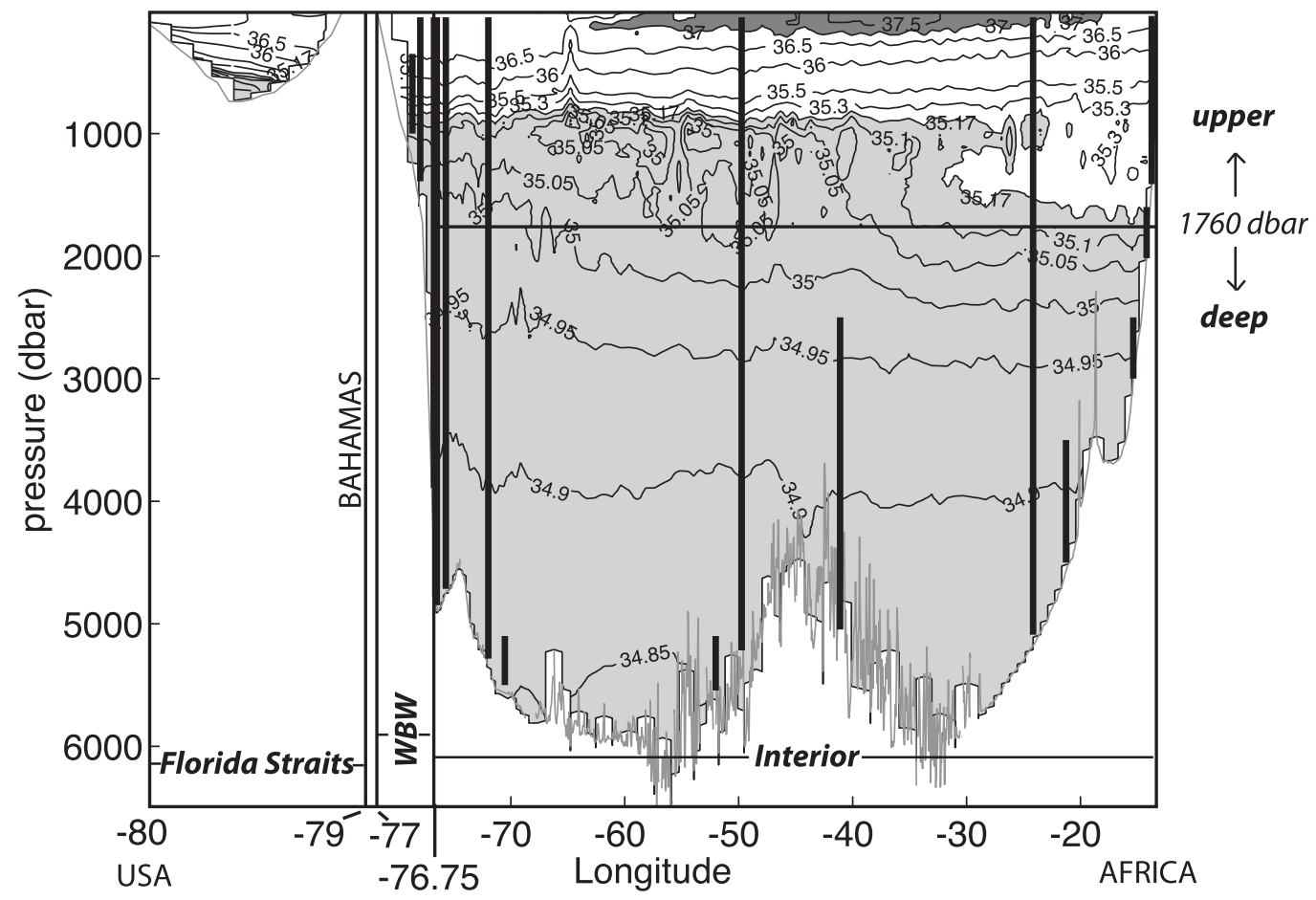

FIG. 2. (a) Potential temperature and (b) salinity for the 2010 occupation of $24.5^{\circ} \mathrm{N}$ hydrographic section. Light gray shading is cooler and fresher than average potential temperature $\left(5.3^{\circ} \mathrm{C}\right)$ and average salinity $(35.17)$ calculated in section 3 from the 8.5 -yr time series. Water more saline than $37 \mathrm{psu}$ is shaded dark gray Note the varying and discontinuous longitude scale. Vertical bold lines indicate the positions of the moorings in the RAPID array. 


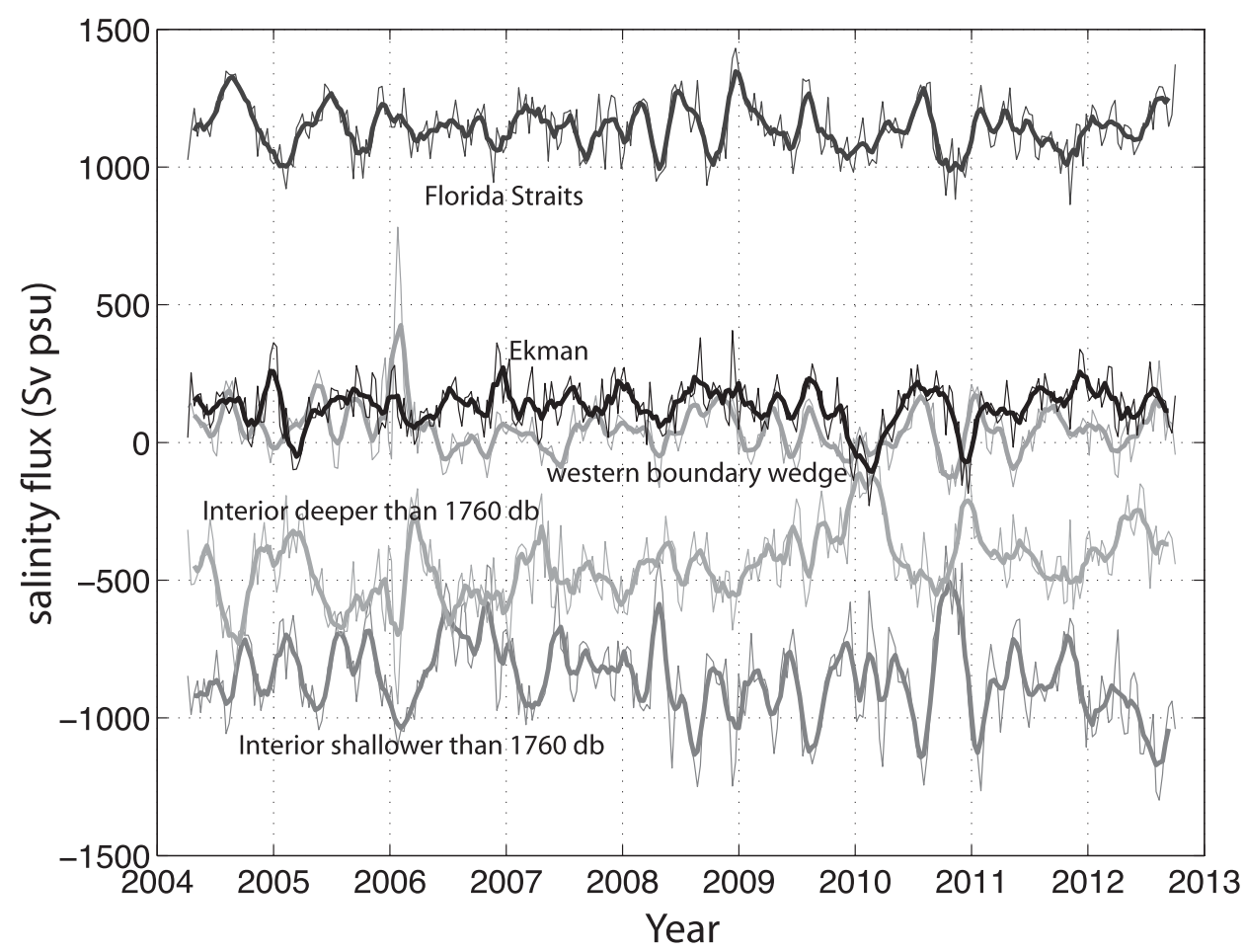

FIG. 3. Ten-day time series of salinity fluxes ( $\mathrm{Sv}$ psu; thin lines) for each subregion. Thick lines are smoothed versions (5-point running mean). Time series run from April 2004 to October 2012. Positive fluxes are northward.

most recent of these hydrographic sections (King 2012) are shown in Fig. 2. Note that while the ends of the hydrographic repeat sections are coincident with the moorings at $26.5^{\circ} \mathrm{N}$, the majority of the CTD stations are further south at $24.5^{\circ} \mathrm{N}$, hence the difference in the nominal latitude of the two observations.

\section{Note on the use of TEOS-10}

The version of the RAPID transport fields used herein was released in July 2013 and included transport estimates between April 2004 and October 2012. This version of the RAPID transports uses International Thermodynamic Equation of Seawater-2010 (TEOS-10; McDougall et al. 2010; McDougall and Barker 2011) to calculate the interior transports from the endpoint moorings as described in McCarthy et al. (2015). To be consistent with the RAPID calculations, all of the velocity estimates that we make here also use the TEOS-10 formulation for density for the dynamical calculations. We combine these estimates of the velocity field with the salinity field on the practical salinity scale to calculate salinity fluxes and thereafter freshwater fluxes. Hereafter we refer to salinity on the practical salinity scale (PSS-78) using the practical salinity unit (psu). Although salinity on this scale formally has no units we use them here to differentiate salinity fluxes (in Sverdrups psu) from volume fluxes (in Sverdrups).

\section{Continuous salinity fluxes}

The salinity flux is defined as

$$
F_{s}=\iint v s d x d z
$$

where the salinity flux $F_{s}$ is given by the horizontal $(x)$ and vertical $(z)$ integral of the salinity $s$ multiplied by the velocity $v$. In some instances, velocity at each point is not available and is replaced by a transport value $T$ for the given region (the integrated velocity over the area) and a transport-weighted salinity that takes account of the salinity field in the context of the velocity field such that

$$
F_{s}=s^{*} T,
$$

where $s^{*}$ is now the transport-weighted salinity. We make our calculations every 10 days (the repeat profiling period of most Argo floats) between April 2004 and October 2012. At each time step a salinity flux is calculated for each subregion at $26.5^{\circ} \mathrm{N}$ [Florida Straits, western boundary wedge (WBW), upper interior (shallower than 1760 dbar), and deep interior (deeper than $1760 \mathrm{dbar}$ )] 
TABLE 1. The salinity flux, transport, transport-weighted salinity, and equivalent freshwater flux for the different regions studied. Negative flows are always southward. The section-average salinity used to calculate the equivalent freshwater flux is 35.17.

\begin{tabular}{|c|c|c|c|c|}
\hline & $\begin{array}{c}\text { Salinity flux (Sv psu): } \\
\text { mean (std dev) }\end{array}$ & $\begin{array}{l}\text { Transport }(\mathrm{Sv}) \text { : } \\
\text { mean (std dev) }\end{array}$ & $\begin{array}{l}\text { Transport-weighted } \\
\text { salinity }\end{array}$ & $\begin{array}{l}\text { Equivalent freshwater } \\
\text { flux (Sv): mean (std dev) }\end{array}$ \\
\hline Florida Straits & $\begin{array}{r}1143.3 \\
(98.2)\end{array}$ & $\begin{array}{l}31.58 \\
(2.71)\end{array}$ & 36.20 & $\begin{array}{c}-0.92 \\
(0.08)\end{array}$ \\
\hline Ekman & $\begin{array}{l}130.8 \\
(95.0)\end{array}$ & $\begin{array}{c}3.53 \\
(2.56)\end{array}$ & 37.05 & $\begin{array}{c}-0.19 \\
(0.14)\end{array}$ \\
\hline Western boundary wedge & $\begin{array}{c}48.3 \\
(105.4)\end{array}$ & $\begin{array}{c}1.30 \\
(2.93)\end{array}$ & 37.15 & $\begin{array}{c}-0.07 \\
(0.08)\end{array}$ \\
\hline Interior (<1760 dbar) & $\begin{array}{c}-861.1 \\
(167.6)\end{array}$ & $\begin{array}{r}-23.65 \\
(4.64)\end{array}$ & 36.41 & $\begin{array}{c}0.83 \\
(0.13)\end{array}$ \\
\hline Interior $(>1760$ dbar $)$ & $\begin{array}{c}-446.2 \\
(145.5)\end{array}$ & $\begin{array}{r}-12.77 \\
(4.17)\end{array}$ & 34.94 & $\begin{array}{c}-0.08 \\
(0.03)\end{array}$ \\
\hline
\end{tabular}

and for the Ekman flux (Fig. 3). We split the interior at $1760 \mathrm{dbar}$ because this is the maximum depth to which Argo floats always profile (at this latitude and for this time period). Here we describe the calculation of the salinity flux in each subregion.

\section{a. Florida Straits}

Submarine-cable-based estimates of transport through the Florida Straits at $27^{\circ} \mathrm{N}$ have been made since 1982 (Baringer and Larsen 2001). The salinity flux through the Florida Straits (Fig. 3) is the product of the average transport of $31.58 \mathrm{~Sv}$ with a standard deviation of $2.71 \mathrm{~Sv}$ (Table 1) and a transport-weighted salinity of 36.2 (Szuts and Meinen 2013). The transport-weighted salinity is an average (standard deviation is 0.049) from 32 ship-based sections of lowered acoustic Doppler current profiler (LADCP) and CTD data collected since 2001 and collocated with the cable measurements. Szuts and Meinen (2013) detected no seasonal or longer-term trend in the transport-weighted salinity for these 32 sections. These estimates of transport-weighted salinity are considered in section 6 in the context of historical estimates of the freshwater flux. The salinity flux through the Florida Straits has a mean value of $1143.3 \mathrm{~Sv}$ psu and a standard deviation of $98.2 \mathrm{~Sv}$ psu (Table 1). As we are using a single transport-weighted salinity, the statistics of this time series are scaled versions of the statistics of the transport time series. Note that all fluxes are positive northward.

\section{b. Ekman}

The Ekman volume flux, driven by surface winds, is calculated from ERA-Interim data and applied to the uppermost 10-dbar cell in our arrays. Predominantly easterly winds drive a northward Ekman transport for this time period of $3.53 \mathrm{~Sv}$ with a standard deviation of $2.56 \mathrm{~Sv}$ (Table 1). The salinity field is from the OI Argo data introduced in section 2. Restricting our Ekman flux to the uppermost cell assumes that the salinity in that cell is representative of the salinity over the Ekman depth. Increasing the depth over which we calculate the Ekman salinity up to 50 dbar has an insignificant impact on the freshwater flux of $0.001 \mathrm{~Sv}$, indicating that applying our Ekman flux to the salinity in the top $10 \mathrm{dbar}$ is reasonable. The resulting Ekman salinity flux (as for the volume flux) is northward with an average value of $130.8 \mathrm{~Sv}$ psu and a standard deviation of 95.0 Sv psu (Table 1).

\section{c. Western boundary wedge}

The WBW is the part of the section that is west of the tall mooring (WB2) at $76.75^{\circ} \mathrm{W}$ (in $3800 \mathrm{~m}$ of water) and east of the Bahamas (Fig. 2). Transports in this region are calculated from direct current meter measurements in contrast to the interior array that calculates transports using dynamic height. Between 7 November 2005 and 26 March 2006 the mooring at $76.75^{\circ} \mathrm{W}$ (WB2) failed and one at $76.5^{\circ} \mathrm{W}$ (WB3, $24 \mathrm{~km}$ east of WB2) was used as the eastern boundary of the WBW. To calculate the salinity flux we combine the RAPID-produced volume flux and the salinity profile from WB2 (or WB3 when WB2 failed). The mean salinity flux for this subregion is $48.3 \mathrm{~Sv}$ psu with a standard deviation of 105.4 Sv psu (Table 1), consisting of a volume flux of $1.30 \pm 2.93 \mathrm{~Sv}$ and a transport-weighted salinity of 37.15 (Table 1).

\section{d. Upper interior (shallower than 1760 dbar)}

In this subregion the salinity field is set to that from the Argo-derived OI. The temperature and salinity fields from the OI are used to calculate the geostrophic velocity between each grid point separated by $0.25^{\circ}$ longitude across the basin. The reference level for calculating geostrophic velocity is set to $1760 \mathrm{dbar}$. This reference level velocity is set (at each time step) to the interior RAPID transport per unit depth divided by the distance, meaning that the OI net transport matches the RAPID net transport for the interior. The vertical structure (or overturning component) of the velocity 
field is still that given by the RAPID array at each time step as the internal velocity variations do not affect the basinwide structure of the velocity. The Argo data add horizontal structure and horizontal components to the velocity and salinity field in the interior. The net interior salinity flux above $1760 \mathrm{dbar}$ is $-861.1 \pm 167.6 \mathrm{~Sv}$ psu (Table 1), associated with a volume flux of $-23.65 \pm$ 4.64 Sv and a transport-weighted salinity of 36.41 (Table 1), where a negative flux is southward.

\section{e. Deep interior (deeper than 1760 dbar)}

The volume flux deeper than 1760 dbar is fully defined by that from the RAPID array. The salinity profile is the average of the endpoint salinity profiles from the moored sensors. Analysis of the repeat hydrographic sections implies that this assumption introduces an insignificant uncertainty (see appendix, section f). Beneath the depth where there are salinity data at both the eastern and western boundaries we extrapolate the salinity profile using the mean vertical structure from the 2010 repeat hydrography data. At each time step the mean 2010 profile is offset so that it matches the deepest good point of the east-west average. This approach for constructing the salinity flux neglects the horizontal salinity flux in this subregion. The horizontal salinity fluxes from the repeat hydrographic sections imply that this component is insignificant in the interior deeper than 1760 dbar (see appendix, section f). The net interior salinity flux deeper than $1760 \mathrm{dbar}$ is $-446.2 \pm 145.5 \mathrm{~Sv}$ psu (Table 1), associated with a net volume flux of $-12.77 \pm$ 4.17 Sv and a transport-weighted salinity of 34.94 (Table 1 ).

\section{f. Converting salinity flux to equivalent freshwater flux}

The salinity flux associated with any of the subregions (Florida Straits, western boundary wedge, upper interior, and lower interior) and the Ekman salinity flux can be converted to an equivalent freshwater flux. This is based on the transport of water at the section-average salinity required to balance the salinity flux in the subregion. This calculation can be thought of in two steps. The net transport $T$ associated with each of the subregions is notionally compensated with a return flow at the section-mean salinity of the 8.5 -yr time series. This section-mean salinity $\bar{s}$ has a value of 35.17 . This results in a zero volume flux flow with an associated salinity flux. The equivalent freshwater flux $F_{e}$ is then the volume flux of water that needs to be added at the section-average salinity to balance this salinity flux:

$$
F_{e}=-\frac{1}{\bar{s}}\left(F_{s}-\bar{s} T\right) \text {. }
$$

As salinity is always positive, for each subregion, the salinity flux is in the same direction as the transport (Table 1).
The equivalent freshwater flux is in the opposite direction to the salinity flux when the transport-weighted salinity $s^{*}$ is greater than the basin-averaged salinity (i.e., a northward salinity flux is associated with a southward freshwater flux). This is the case for all the subregions apart from the interior deeper than $1760 \mathrm{dbar}$, where the transport-weighted salinity is less than the section-average salinity (Table 1). The equivalent freshwater fluxes show a dominant balance between the Florida Straits $(-0.92 \mathrm{~Sv})$ and the upper interior $(0.83 \mathrm{~Sv})$. The equivalent freshwater flux indicates the strength, balance, and sign of the component parts of the observation system (subregions) relative to the total freshwater flux.

\section{Components of continuous freshwater flux}

\section{a. Total freshwater flux and freshwater divergence}

The total freshwater flux is calculated at each time step by calculating the salinity flux across the entire section and setting the section salinity transport equal to the Bering Strait salinity flux of $-26 \mathrm{~Sv}$ psu based on Woodgate et al. (2005). Applying this constraint is equivalent to assuming that salt is conserved between the Bering Strait and $26.5^{\circ} \mathrm{N}$. We further assume that the freshwater flux is equivalent to the volume flux as in Bryden et al. (2011). Formally the freshwater flux is the portion of the mass flux that is not salt. At the Bering Strait this assumption introduces a $0.7 \%$ uncertainty in the freshwater flux based on the values given in Wijffels et al. (1992), where the volume flux is $0.8 \mathrm{~Sv}$ and the freshwater mass flux is $0.794 \times 10^{9} \mathrm{~kg} \mathrm{~s}^{-1}$. This uncertainty is small and we do not consider the impact of this assumption further. The freshwater flux $F_{w}$ is the volume flux added at each time step at the sectionaverage salinity of 35.17 so that when combined with the salinity flux from the subregions it gives a net salinity flux of $-26 \mathrm{~Sv}$ psu ( $0.8 \mathrm{~Sv}$ at a salinity of $32.5 \mathrm{psu})$ :

$$
F_{W}=-\frac{1}{\bar{s}}\left(F_{s}-F_{s}^{\mathrm{BS}}\right),
$$

where the salinity flux $F_{s}$ is the sum for all of the subregions and $F_{s}^{\mathrm{BS}}$ is the Bering Strait salinity flux of $-26 \mathrm{~Sv}$ psu.

The total freshwater flux (Fig. 4) can be interpreted as a volume flux across the section of $-1.17 \mathrm{~Sv} \pm 0.20 \mathrm{~Sv}$ (mean plus or minus standard deviation) where negative transports are southward. The most meaningful part of this time series is the difference between the total freshwater flux and the volume flux through the Bering Strait (0.8 Sv; horizontal gray line in Fig. 4); we refer to this difference $(-0.37 \pm 0.20 \mathrm{~Sv})$ as the freshwater divergence $F_{d}$. Thus there is a net freshwater input into the ocean between the Bering Strait and $26.5^{\circ} \mathrm{N}$. This 


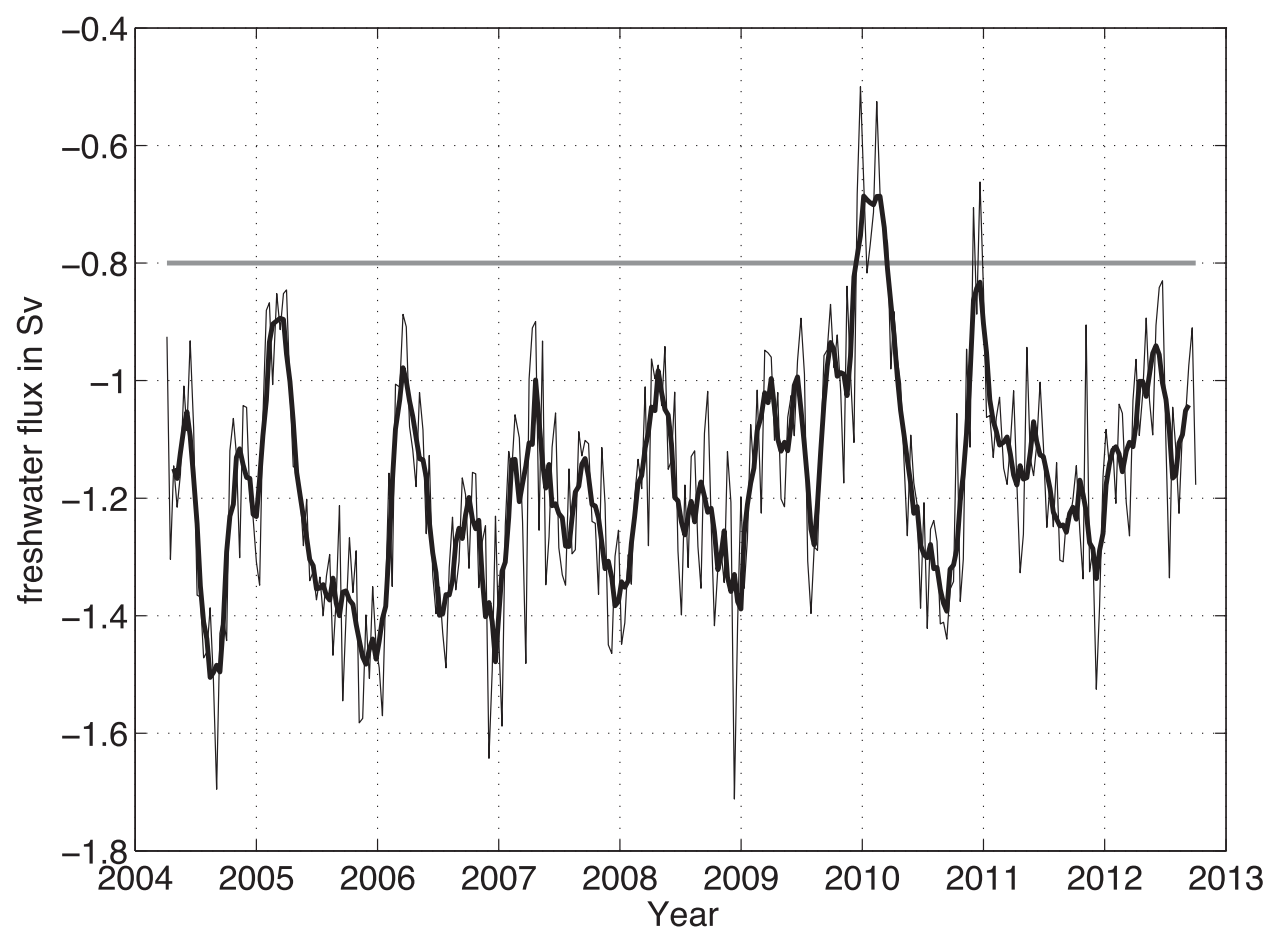

FIG. 4. Ten-day time series of freshwater flux across $26.5^{\circ} \mathrm{N}$ (thin line) from April 2004 to October 2012. Thick line is smoothed version (5-point running mean). Freshwater flux is the volume flux across the section (Sv). The difference between the freshwater flux and the volume flux through the Bering Strait $(-0.8 \mathrm{~Sv}$; gray line $)$ is the freshwater divergence between the Bering Strait and $26.5^{\circ} \mathrm{N}$.

freshwater divergence includes contributions from evaporation, precipitation, river runoff, ice melt-formation, and freshening/increase in salinity of the water column (i.e., changes in storage of freshwater) in the region between $26.5^{\circ} \mathrm{N}$ and the Bering Strait. This is a bulk estimate, so contributions from different processes cannot be discerned without reference to other information. The uncertainty on any 10-day estimate is $0.05 \mathrm{~Sv}$ (see section 5 and the appendix).

Averaging the freshwater flux based on day of year reveals the seasonal cycle (Fig. 5a). There is smaller southward freshwater flux in the first half of the year with a minimum of $-0.98 \mathrm{~Sv}$ in April (day 95). The second half of the year shows a (mostly) larger-than-average southward freshwater flux with a maximum value of $-1.31 \mathrm{~Sv}$ reached in July, August, and December (between days 205 and 345).

The freshwater flux changes significantly from year to year. We calculate the annual average of the time series from April to March for each of the 8 full years of the time series (Fig. 5b). The uncertainty on the annual average (determined in section 5 and the appendix) is $0.02 \mathrm{~Sv}$. Most of the annual averages fall into the range from -1.14 to -1.30 Sv, with one year [April 2009-March 2010 (year 6)] showing a notably lower annual average of $-0.96 \mathrm{~Sv}$. Year 6 is also associated with the lowest annual average
MOC strength (Fig. 5b) calculated by Smeed et al. (2014). We quantify the relationship between the freshwater flux and the MOC in section $4 d$.

\section{b. Components of the freshwater divergence}

The freshwater divergence is split into components to discern which elements of the circulation are associated with the salinity (and therefore freshwater) flux (as in Bryden et al. 2011). The freshwater divergence is divided into three components: throughflow, overturning, and horizontal (Fig. 6). We decompose the total velocity and salinity into throughflow, overturning, and horizontal components as such:

$$
\begin{aligned}
& v=\bar{v}+\langle v\rangle(z)+v^{\prime}(x, z) \quad \text { and } \\
& s=\bar{s}+\langle s\rangle(z)+s^{\prime}(x, z),
\end{aligned}
$$

where the overbar indicates a full basinwide (vertical and horizontal) average, the angle brackets indicate zonally averaged deviations from the basinwide average, and the prime indicates residual deviations from the zonal average.

\section{1) Throughflow COMPOnEnT}

The throughflow component of the freshwater divergence is associated with the change in salinity of the Bering Strait throughflow between the Bering Strait and $26.5^{\circ} \mathrm{N}$ : 
a) mean annual cycle (Apr2004-Oct2012) +- standard deviation

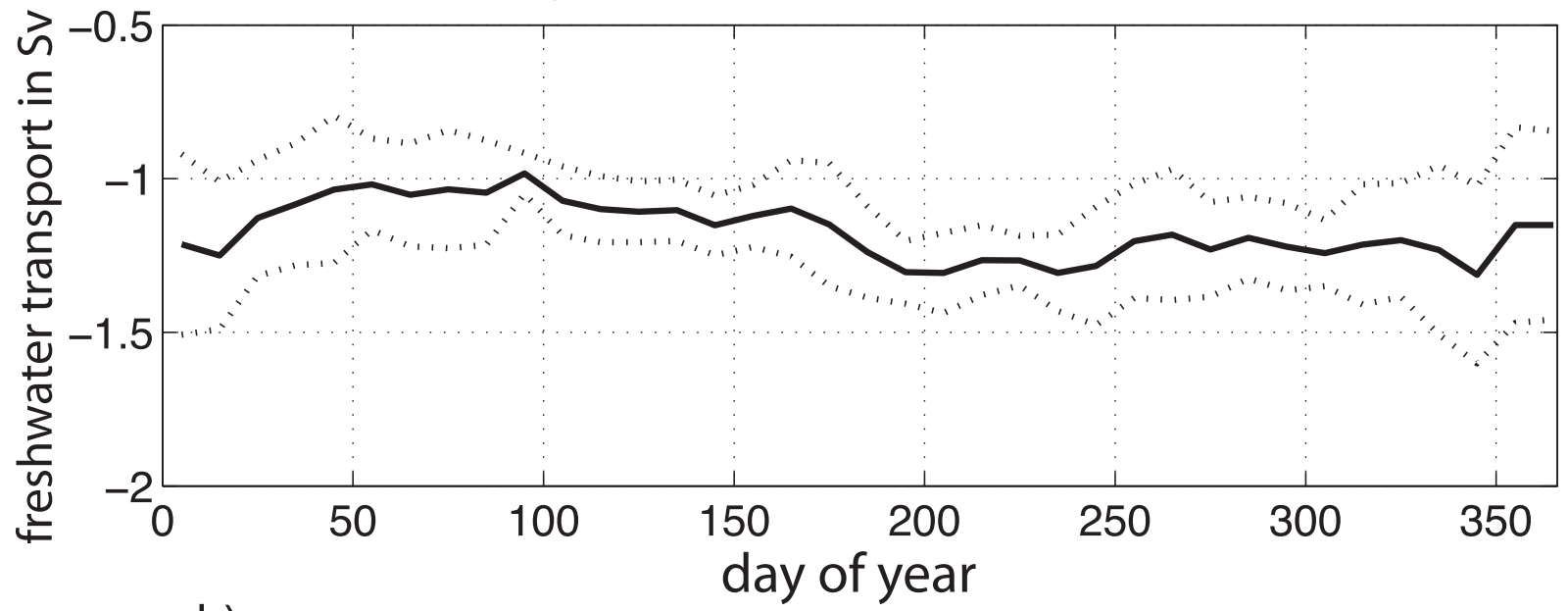

b)

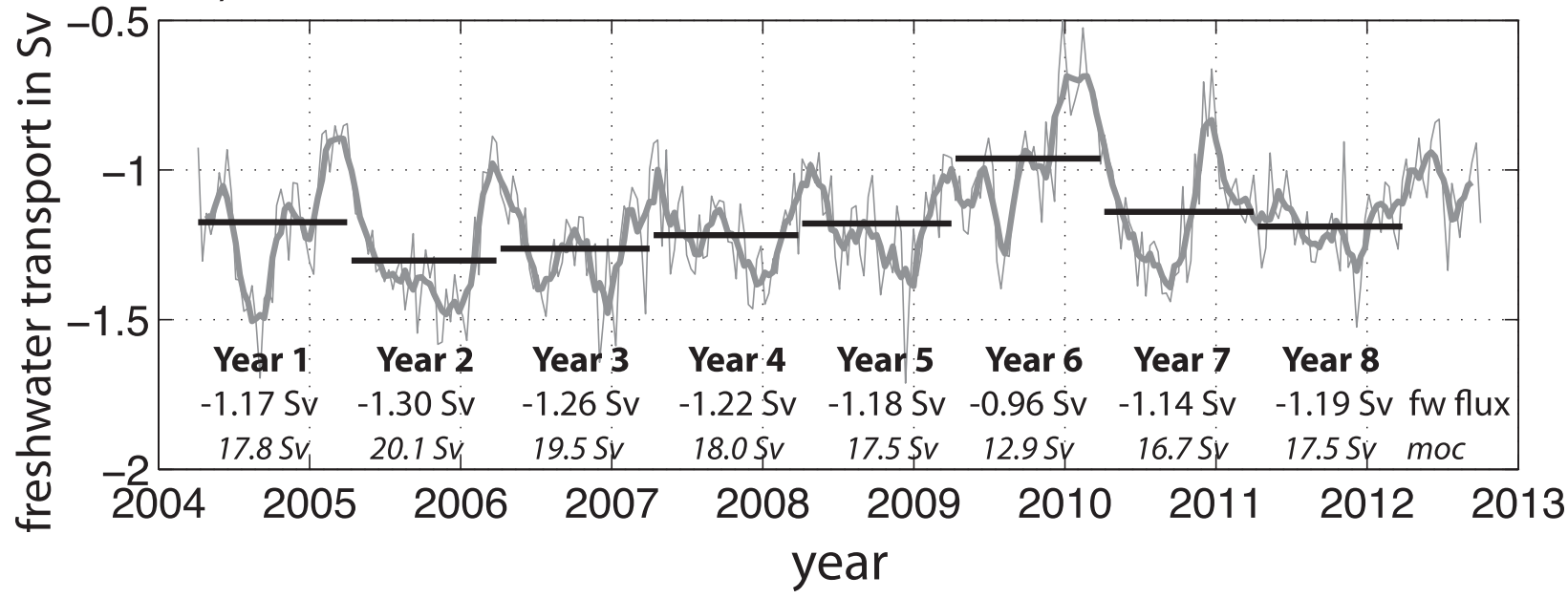

FIG. 5. (a) Average (solid line) plus or minus standard deviation (dotted lines) of 8.5 annual cycles of freshwater flux interpolated onto day of year every 10 days from day 5. (b) Annual average of freshwater flux (horizontal lines and values) for each year of the 8 full years in the time series. Each annual average represents 12 months from April. Values in italics are the strength of the MOC calculated from the RAPID array for the same year (Smeed et al. 2014).

$$
F_{d}^{t}=-\frac{0.8 \mathrm{~Sv} \times(32.5-35.17)}{35.17}=0.06 \mathrm{~Sv}
$$

where the throughflow component of the freshwater divergence $F_{d}^{t}$ is associated with the $0.8 \mathrm{~Sv}$ of Bering Strait flow increasing in salinity from 32.5 at Bering Strait to 35.17 at $26.5^{\circ} \mathrm{N}$. The increase in salinity is associated with a loss of freshwater between the Bering Strait and $26.5^{\circ} \mathrm{N}$ and a northward freshwater flux across $26.5^{\circ} \mathrm{N}$ that acts to increase salinity. This component is relatively small $(0.06 \mathrm{~Sv})$ and is constant as a result of using a constant section-average salinity (35.17). When a time-varying section-average salinity is used (not shown here) the time variability of this component is insignificantly small. Note that variability in the Bering Strait salinity flux is accounted for in the uncertainty calculation (see appendix, section $\mathrm{h}$ ).

\section{2) OVERTURNING COMPONENT}

The overturning component of the freshwater divergence $F_{d}^{o}$ is the combination of the overturning salinity and overturning circulation across all subregions, including the Florida Straits. The overturning components of salinity and velocity are the zonally averaged fields of salinity $\langle s\rangle$ or velocity $\langle v\rangle$ with the section average removed as defined in Eqs. (5) and (6).

$$
F_{d}^{o}=-\frac{1}{s} \int T(z)[\langle s\rangle(z)] d z, \text { where }
$$




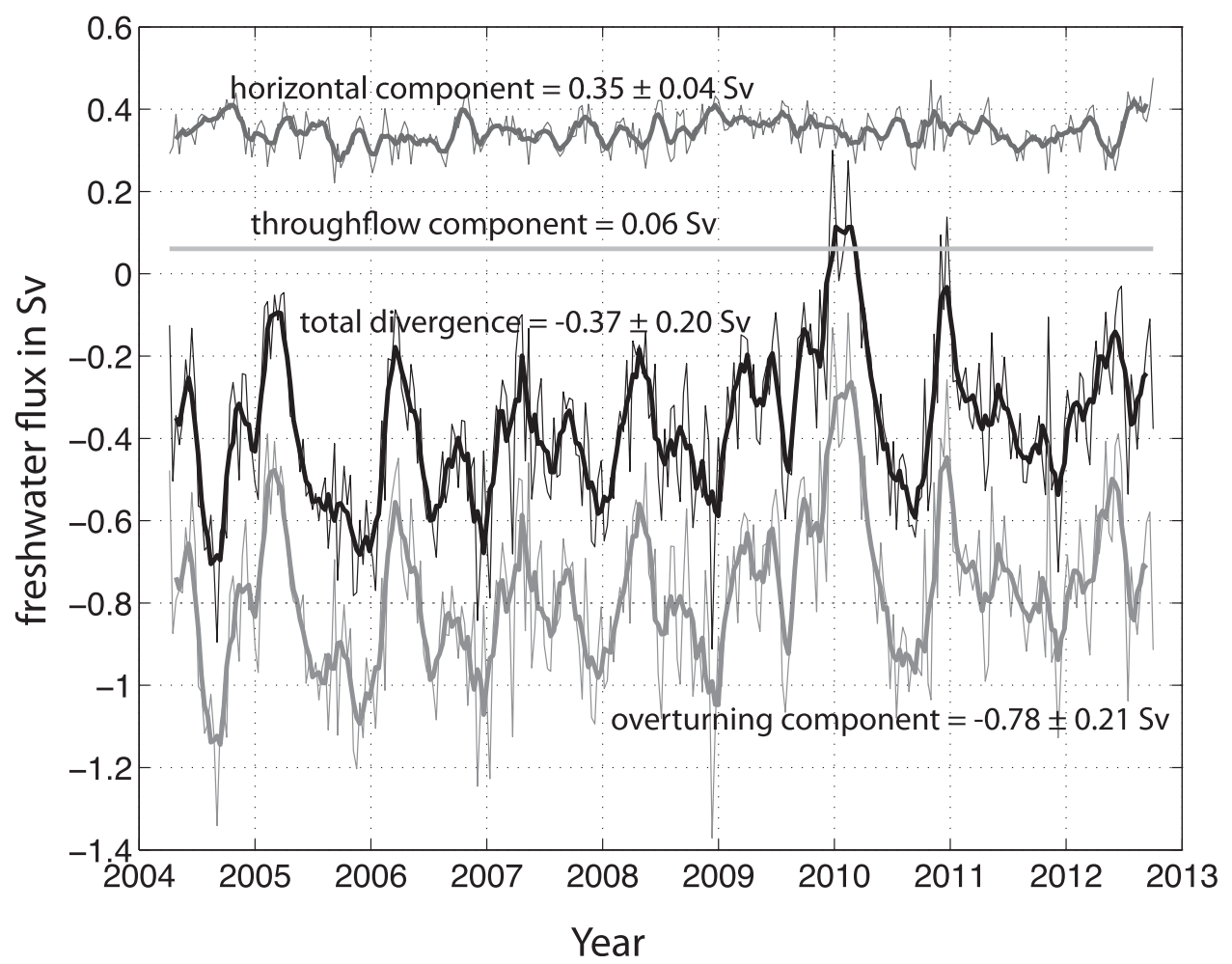

FIG. 6. Components (gray lines) of the total freshwater divergence in black. Ten-day time series (thin lines) and smoothed version (thick lines; 5-point running mean). Numbers indicate mean plus or minus standard deviation of 10-day time series.

$$
T(z)=\int\langle v\rangle(z) d x .
$$

The overturning component of the freshwater divergence has a mean value of $-0.78 \mathrm{~Sv}$ and a standard deviation of $0.21 \mathrm{~Sv}$; it is the largest and most variable component (Fig. 6). This component of the salinity divergence is associated with a northward salinity flux and a southward freshwater flux. This reflects the balance between northward-flowing high-salinity surface waters and the compensating southward flow of relatively fresh deep waters.

\section{3) HORIZONTAL COMPONENT}

The horizontal component $F_{d}^{h}$, including the gyre and eddy components, reflects correlations in the residual velocity and salinity fields. These residual fields are defined as those with the mean and overturning components removed, as defined in Eqs. (5) and (6).

$$
F_{d}^{h}=-\frac{1}{\bar{s}} \iint\left[v^{\prime}(x, z)\right]\left[s^{\prime}(x, z)\right] d x d z
$$

The horizontal freshwater flux is consistently positive with a mean of $0.35 \mathrm{~Sv}$ and a standard deviation of $0.04 \mathrm{~Sv}$ (Fig. 6). This component of the freshwater divergence always transports salinity southward and freshwater northward. This reflects the balance between the northward-flowing Florida Current and the interior upperocean return flow in the relatively saline gyre interior.

\section{c. Heat flux}

Using an analogous method for temperature as for salinity, we derive a heat flux across the $26.5^{\circ} \mathrm{N}$ section. As in the Johns et al. (2011) study, the section is constrained to zero net volume flux. The resulting $8.5-\mathrm{yr}$ time series of heat flux every 10 days has a mean value of 1.24 PW $\left(10^{15} \mathrm{~J} \mathrm{~s}^{-1}\right)$ and a standard deviation of 0.33 $\mathrm{PW}$. This is consistent with the updated monthly estimates of Johns et al. (2011; mean of 1.25 PW and standard deviation of $0.36 \mathrm{PW}$ ) that now incorporate Argo data in the interior (McCarthy et al. 2015).

The time series of heat flux and its horizontal and overturning components are shown in Fig. 7. Unlike the freshwater flux, the overturning and horizontal components act in the same direction, both transporting heat northward. Similar to the freshwater flux, the overturning component of the heat flux is the largest component and exhibits the most variability. The relationships between the MOC strength and the total heat and freshwater fluxes are quantified next. 


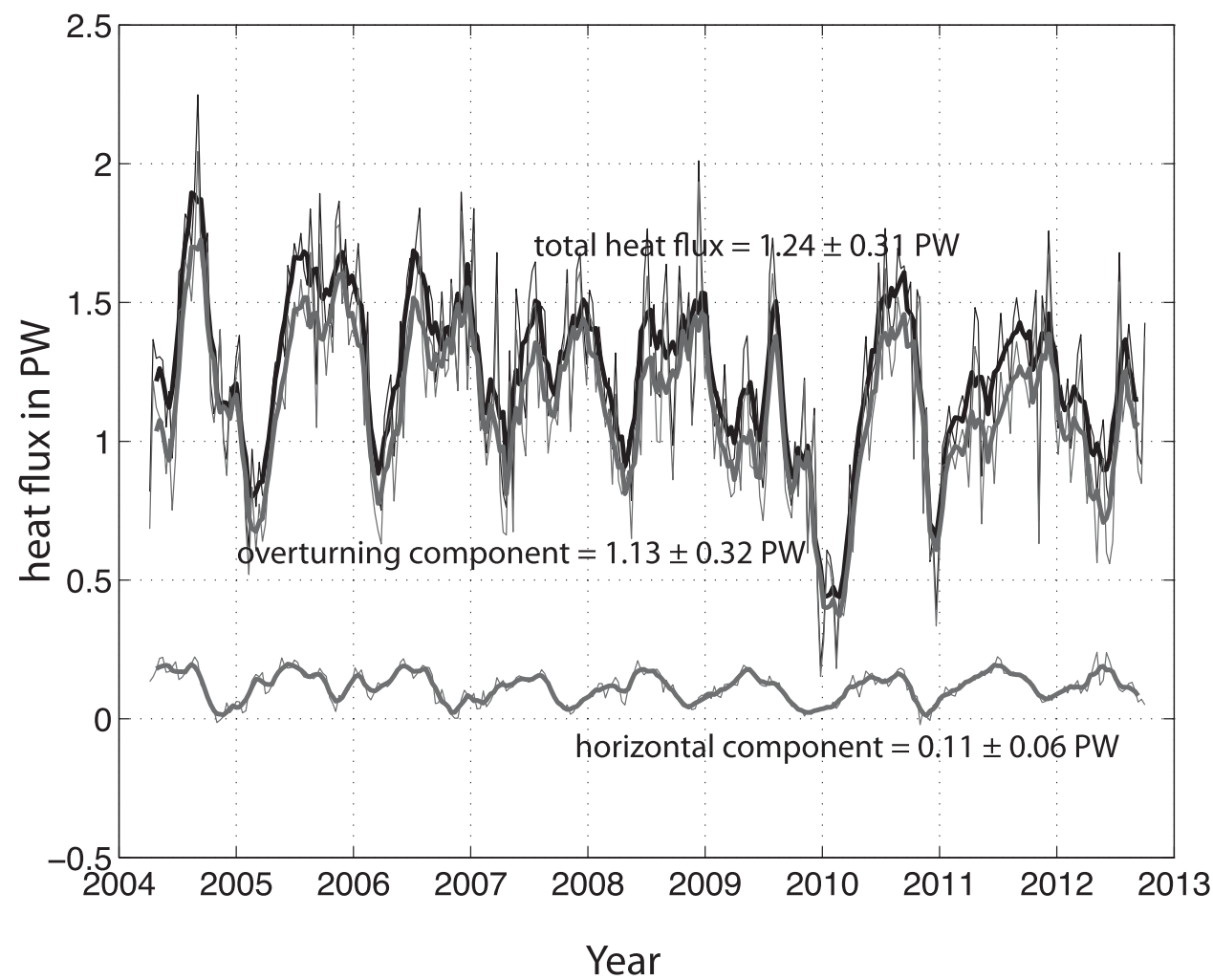

FIG. 7. Eight and a half year time series of total heat flux across $26.5^{\circ} \mathrm{N}$. Horizontal and overturning components of heat flux are shown in gray. The 10-day time series are shown in thin lines; smoothed versions (5-point running mean) are shown in thicker lines. Numbers indicate mean plus or minus standard deviation of 10-day time series.

\section{d. Relationship between freshwater and heat fluxes and $M O C$}

We find a strong linear relationship between the freshwater flux and the MOC derived from the array that describes $91 \%$ of the variance (Fig. 8). The freshwater flux in Sverdrups equals $-0.37-0.047 \times$ MOC. We find a strong linear dependence of heat flux on MOC that explains $92 \%$ of the variance, such that heat flux in petawatts equals $-0.09+0.078 \times$ MOC (Fig. 8). The nonzero intercept of these relationships reflects that part of the flux that is not described by the MOC. Broadly we interpret this as a combination of the horizontal flux and some uncertainty in both the estimates and the model of linear dependence on the MOC. The sensitivity (or gradient) of both the heat and freshwater dependencies on MOC indicates that an increase in MOC is associated with an increase in northward heat flux and an increase in southward freshwater flux (or an increase in northward salinity flux).

Figure $8 \mathrm{~b}$ shows that the majority of the variability in our freshwater flux time series can be described by variability in the strength of the MOC. A linear fit to the freshwater flux time series in Fig. 4 gives an increase in freshwater flux of $0.023 \mathrm{~Sv} \mathrm{yr}^{-1}$. This increase can, within uncertainties, be accounted for by the observed decrease in the MOC of $0.54 \mathrm{~Sv} \mathrm{yr}^{-1}$ (Smeed at al. 2014) and the freshwater sensitivity to the MOC of $0.047 \mathrm{~Sv} \mathrm{~Sv}^{-1}$. Thus, the decreasing MOC accounts for an increase in freshwater flux of $0.025 \mathrm{~Sv} \mathrm{yr}^{-1}(=0.54 \times 0.047)$. However, there is structure in the residuals to the freshwater flux dependence on the MOC. The residuals (Fig. 8c) show a statistically significant (at the $97.5 \%$ level) reduction over time. A positive residual is consistent with a smaller-magnitude (less negative) freshwater flux for the same MOC. The implication of the structure in the residuals is that over the 8.5-yr time series the same MOC is associated with an increased southward freshwater flux. This is consistent with a change in the salinity field in the sense of an increase in upper-ocean salinity. However, the magnitude of the total change over $8.5 \mathrm{yr}$ is small-a total of $0.02 \mathrm{~Sv}$. Thus, the variability in the 8.5-yr freshwater flux time series that is not described by the MOC is detectable but small.

The overturning circulation is associated with a southward density flux as the southward-flowing deep 
a)

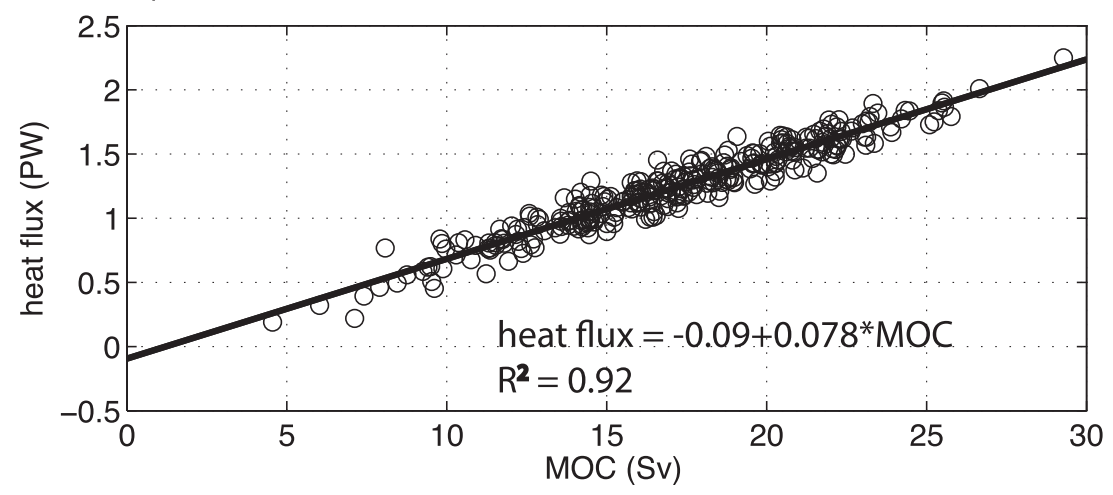

b)
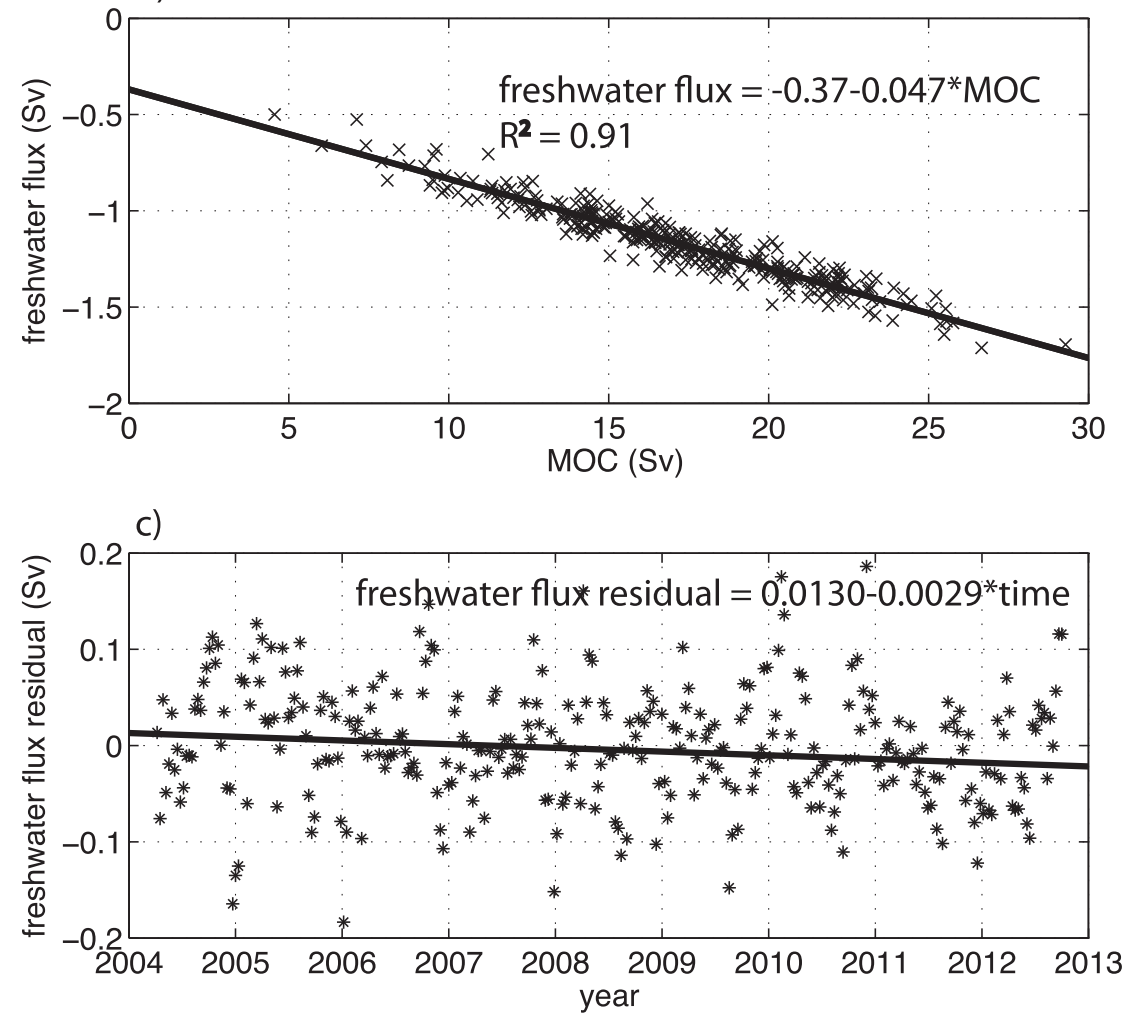

FIG. 8. (a) Heat flux and (b) freshwater flux vs MOC strength derived from the array. The black line shows the linear fit to these estimates. (c) The freshwater flux residual from the linear fit in (b) plotted against year; time in the linear fit is year minus 2004; estimate of the slope $(-0.0029)$ is more than twice the standard error (0.0014), and so the slope is negative with $p>0.975$.

water is denser than the northward-flowing upper water. The thermal contribution to the density flux is also southward, as the overturning circulation is associated with northward-flowing, warmer (less-dense thermal component) water over southward-flowing, colder (denser thermal component) water. The haline contribution to the density flux is northward as the overturning circulation is associated with northward-flowing, more saline (denser haline component) water over southward-flowing, less saline (less-dense haline component) water. Here we quantify the thermal and haline contributions to the density flux in terms of changes in the MOC.

The sensitivities of heat and salinity (freshwater) fluxes to changes in the MOC have opposing effects on the density flux. A positive change in MOC increases the northward temperature flux and increases the southward density flux, where the same MOC change increases the northward salinity flux (increases the southward freshwater flux) and 
TABLE 2. Component salinity and freshwater fluxes across $24.5^{\circ} \mathrm{N}$ for six hydrographic repeat sections calculated relative to $0.8 \mathrm{~Sv}$ at salinity 32.5 through the Bering Strait. Transport estimates (in parentheses) used for salinity are from Atkinson et al. (2012). Florida Straits salinity flux, total salinity flux, freshwater flux across $24.5^{\circ} \mathrm{N}$, and freshwater divergence between $24.5^{\circ} \mathrm{N}$ and the Bering Strait using transport-weighted salinity of 36.2 from Szuts and Meinen (2013; column a) or literature values of transport-weighted salinity (Fig. 9; column b). The mid-ocean salinity is the area-weighted average east of the Bahamas.

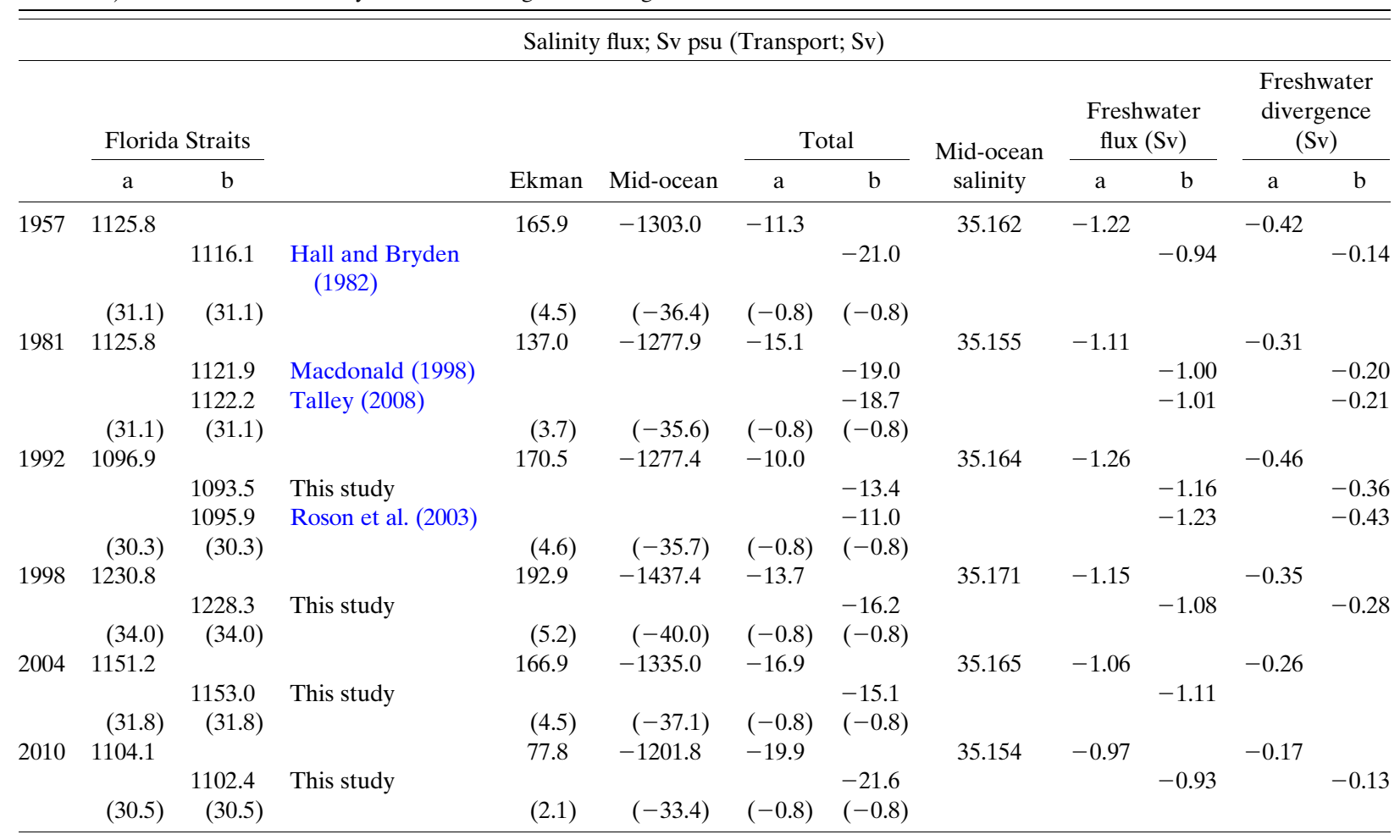

increases the northward density flux. A thermal expansion coefficient $\alpha$ of $2.17 \times 10^{-4}{ }^{\circ} \mathrm{C}^{-1}$ and a haline contraction coefficient $\beta$ of $7.51 \times 10^{-4} \mathrm{psu}^{-1}$ represent the upper arm of the MOC at a salinity of 36 and temperature of $15^{\circ} \mathrm{C}$. The sensitivity of the density flux is $-4.24 \mathrm{~Sv} \mathrm{~kg} \mathrm{~m}^{-3}$ per Sverdrups change in MOC associated with the heat flux and $1.27 \mathrm{~Sv} \mathrm{~kg} \mathrm{~m}^{-3}$ per Sv change in MOC associated with the salinity flux. Thus, the temperature dominates the density flux associated with the MOC and the net sensitivity of the density flux is $-2.97 \mathrm{~Sv} \mathrm{~kg} \mathrm{~m}^{-3}$ per Sverdrups change in MOC, where a negative density flux is southward.

\section{Uncertainty}

A full description of the uncertainty calculation is contained in the appendix. In summary, the total uncertainty in each 10-day estimate of salinity flux is $1.9 \mathrm{~Sv}$ psu, which equates to $0.05 \mathrm{~Sv}$ in freshwater divergence. For each element of the calculation the transport-derived uncertainty is larger than the salinity-derived uncertainty, and the largest uncertainty is associated with the transport uncertainty in the Florida Straits.
Assuming that there are 12 independent estimates in the year, gives an uncertainty on the annual mean of $0.02 \mathrm{~Sv}$.

\section{Historical estimates of freshwater flux}

The freshwater flux across $24.5^{\circ} \mathrm{N}$ using data from the six transatlantic hydrographic repeat sections of this section (Fig. 1) was computed using the geostrophic transport field in the mid-ocean (east of the Bahamas) and the Ekman volume flux and Florida Straits transport from Atkinson et al. (2012). The Florida Straits transport was based on the appropriate annual average for the cable transport (Baringer and Larsen 2001; pre-cable estimates in 1957 and 1981 were based on a long-term average of $31.1 \mathrm{~Sv}$ ). Ekman transports (also an annual average) were calculated from gridded surface wind stress fields from the NCEP-NCAR reanalysis (Kalnay et al. 1996; Kistler et al. 2001).

The Atkinson et al. (2012) transport estimates (numbers in parentheses in Table 2) were combined with an appropriate salinity to calculate the salinity flux across the section. For the Ekman salinity we used the average salinity from the CTD data in the top $10 \mathrm{dbar}$. In the 
mid-ocean the average station-pair salinity appropriate to the geostrophic transport was used. In the Florida Straits we use either 1) a transport-weighted salinity of 36.2 (Szuts and Meinen 2013) representative of 2001-10 or 2) a transport-weighted salinity from the literature, usually from data contemporaneous with the middleocean section. For the 2004 and 2010 occupations we calculate a transport-weighted salinity in the Florida Straits by combining the LADCP and CTD salinity data.

As an example of how the values in Table 2 are generated for the 1957 data using the historical Florida Straits transport-weighted salinity, the total salinity flux equals the sum of the Florida Straits, Ekman, and mid-ocean salinity fluxes (i.e., $1116.1+165.9-1303.0=-21 \mathrm{~Sv}$ psu). The freshwater flux equals $-0.8 \mathrm{~Sv}$ minus (total salinity flux $+26 \mathrm{~Sv}$ psu) divided by mid-ocean salinity. This formulation is slightly different from that in Eq. (4) because the Atkinson et al. (2012) transports were calculated to give a 0.8-Sv southward flow. For the 1957 example the net freshwater flux is given by $-0.8 \mathrm{~Sv}-(-21+26) /$ $35.162=-0.94 \mathrm{~Sv}$. The freshwater divergence is then the difference between the freshwater flux and the volume flux through the Bering Strait: $(-0.94+0.8 \mathrm{~Sv})=-0.14 \mathrm{~Sv}$.

Table 2 contains estimates of the freshwater flux and freshwater divergence for each of the six hydrographic repeat sections using modern or contemporaneous transport-weighted salinity estimates in the Florida Straits. When the Szuts and Meinen (2013) transport-weighted salinity for the Florida Straits (36.2) is used, the mean freshwater flux across $24.5^{\circ} \mathrm{N}$ from these six hydrographic sections is $-1.14 \mathrm{~Sv}$, with a standard deviation of $0.08 \mathrm{~Sv}$. This implies an average input of freshwater of $0.34 \mathrm{~Sv}$ between $24.5^{\circ} \mathrm{N}$ and the Bering Strait. Using the Florida Straits data contemporaneous with the mid-ocean section to evaluate the Florida Straits transport-weighted salinity gives a southward freshwater flux (and negative freshwater divergence) that is generally less than that using the Szuts and Meinen (2013) value for transport-weighted salinity. The difference is largest $(0.28 \mathrm{~Sv})$ for the oldest (1957) section.

The detail of the elements of the freshwater calculation in the Hall and Bryden (1982) paper allows us to examine the difference between the oldest of the historical measurements and our estimates using the modern transport-weighted salinity in the Florida Straits. The major contributor to the difference between our implied divergence for the 1957 data (0.42 Sv; Table 2) and the Hall and Bryden (1982) estimate of $0.03 \mathrm{~Sv}$ is the transport-weighted salinity in the Florida Straits. Hall and Bryden (1982) use a transport-weighted salinity of 35.886 in the Florida Straits, while we use the Szuts and Meinen (2013) value of 36.2. As the Florida Straits flow is approximately $30 \mathrm{~Sv}$, this increase in the transport-weighted salinity increases the northward salinity flux by (36.197$35.886) \times 30 \mathrm{~Sv}$ psu $=9.33 \mathrm{~Sv}$ psu. This larger northward salinity flux [of our estimate relative to Hall and Bryden (1982)] increases the southward freshwater flux by $9.33 /$ $35.16 \mathrm{~Sv}=0.27 \mathrm{~Sv}$. The maximum difference between any of the other components in the Hall and Bryden (1982) freshwater flux calculation and our calculation for the 1957 data is $0.06 \mathrm{~Sv}$. Thus, the majority of the difference between our estimate of the freshwater flux from the 1957 data using the modern transport-weighted salinity in the Florida Straits and that of Hall and Bryden (1982) is due to the salinity field in the Florida Straits.

While we cannot explore a similar decomposition for all of the historical estimates, we can explore the variability of the transport-weighted salinity in the Florida Straits using the multiple estimates of Szuts and Meinen (2013) and the one-off estimates from the repeat hydrography that are recorded in the literature (Fig. 9). Hall and Bryden (1982) estimate their transport-weighted salinity for the Florida Straits using the 1974 data of Brooks and Niiler (1977), as the 1957 section sampled only east of the Bahamas. The Szuts and Meinen (2013) estimate comes from 32 repeat hydrographic and LADCP sections made between 2001 and 2010 across the Florida Straits.

Estimates of the transport-weighted salinity from the two most recent occupations (2004 and 2010) lie within the cloud of the Szuts and Meinen (2013) estimates that envelop them in time. The estimates from different authors using 1981 data agree well (better than the 0.03 salinity uncertainty in Table A1); the same is true for the multiple estimates from the 2004 data. In 1992 the multiple estimates agree less well. This occupation of the Florida Straits was exceptional because, as a result of a faulty echo sounder, the CTD did not measure within $200 \mathrm{~m}$ of the bottom, requiring extrapolation through the deepest $200 \mathrm{~m}$. The variability in the transport-weighted salinities is likely a result of the exact method of extrapolation used for the 1992 data. Earlier transects (1974 and 1981) have smaller transport-weighted salinities that lie outside the range of variability measured from 2001 to 2010. The impression from all of these estimates is that the transport-weighted salinity has increased in time (Fig. 9); however, using these synoptic repeats it is impossible to say whether this increase is systematic. A rough estimate of the accuracy of a single transect is provided by the standard deviation of the 32 estimates from Szuts and Meinen (2013), which is 0.049. The 1974 estimate using the Brooks and Niiler (1977) data lies outside of the Szuts and Meinen (2013) cloud of points and is more than six standard deviations away from the mean. Therefore, we can say that the transport-weighted salinity is significantly different in 1974 from what it was in the 2000 s, by an amount of $0.314 \pm 0.049$. 


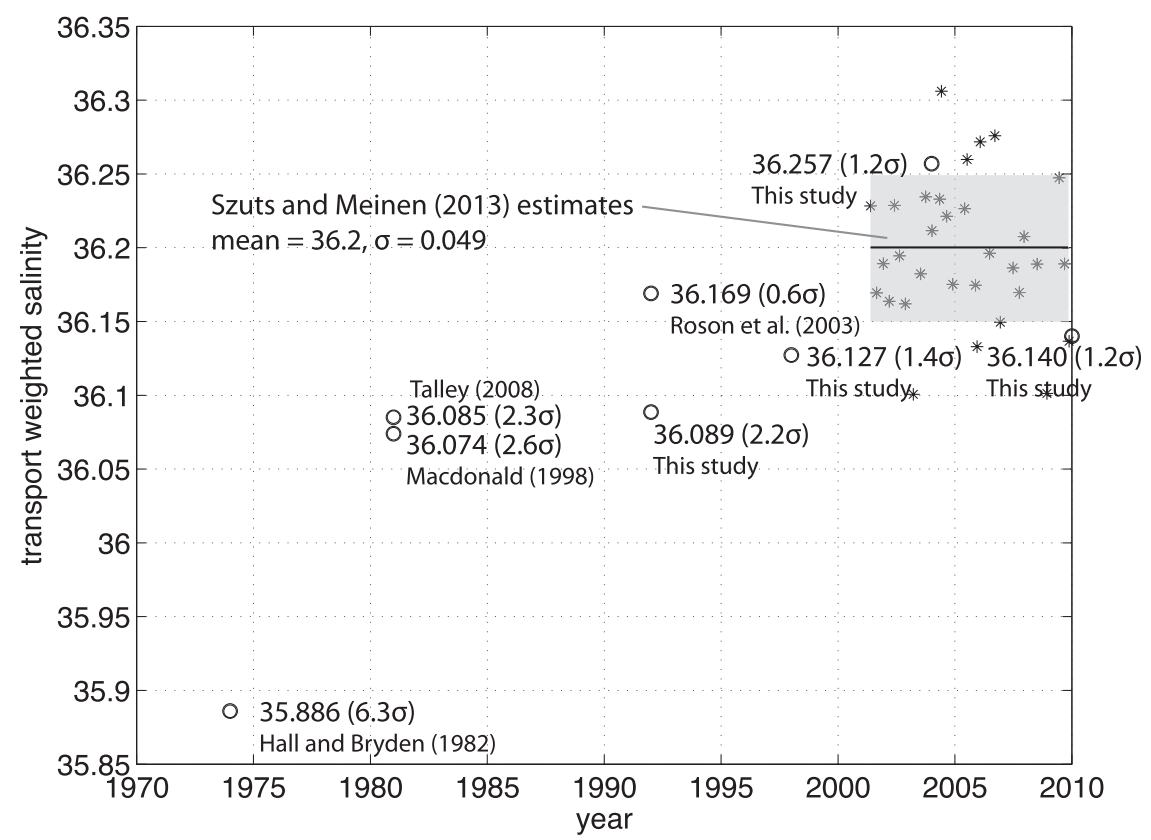

FIG. 9. Estimates of the transport-weighted salinity from the literature and used in Table 2. The shaded region represents the plus or minus one standard deviation from the mean (horizontal line) of the Szuts and Meinen (2013) estimates for the time period over which estimates were made. The number in parentheses after each transport-weighted salinity represents the number of standard deviations that the literature value lies away from the Szuts and Meinen (2013) mean of 36.2.

\section{Summary and discussion}

We derive a time series of the oceanic freshwater flux across $26.5^{\circ} \mathrm{N}$ in the Atlantic that implies an average net input of freshwater to the ocean of $0.37 \mathrm{~Sv}$ between the Bering Strait and $26.5^{\circ} \mathrm{N}$. The sign of this freshwater divergence is in the sense of increased precipitation over evaporation or increasing oceanic salinity.

The strength and variability of freshwater divergence is dominated by the overturning component of ocean circulation. It is therefore not surprising that there is a strong linear relationship between the freshwater flux (freshwater divergence minus $0.8 \mathrm{~Sv}$ ) and the strength of the MOC.

The overturning freshwater flux is associated with a haline component of the density flux that is northward, consistent with northward-flowing upper water that is more saline, and has a more dense haline component than the southward-flowing, fresher deep water with a less dense haline component. This density flux is more than compensated by the southward thermal component of the density flux, consistent with northwardflowing upper water that is warmer has a less dense thermal component and southward-flowing deep water that is colder and has a more dense thermal component. Thus, the thermal component of the density flux dominates the sign of the density flux sensitivity to variability in the MOC.
While the majority of the variability in the freshwater divergence can be described by variability in the MOC, there is a detectable but small change over time in the residual to this relationship. We interpret this as a coherent change in the salinity flux such that for the same overturning circulation more salt is transported northward and more freshwater is transported southward. There is an indication of a seasonal cycle in the freshwater divergence, with a smaller divergence in the first six months of the year and a larger (more negative) divergence in the second half of the year.

We find significant interannual variability in the time series; however, all recent annual averages imply a larger divergence than the historical estimate of nearzero divergence from Hall and Bryden (1982). Recalculating the freshwater fluxes from the historical hydrographic sections using both the historical and modern transport-weighted salinity in the Florida Straits indicates that the difference between the near-zero divergence for the 1957 section and modern estimates is primarily due to changes in the transport-weighted salinity in the Florida Straits, which changed from 35.886 in the Hall and Bryden (1982) estimate to 36.2 in the Szuts and Meinen (2013) estimate. From the repeat hydrography it is impossible to tell if this is a systematic difference. However, this increase of $0.314 \pm 0.049$ is consistent with the Durack and Wijffels (2010) surface 
increase in salinity of $>0.2 \mathrm{psu}$ in the region of the Florida Straits over 50 years between 1950s and 2000s. The apparent change in the upper-ocean salinity flowing through the Florida Straits implies that the strength of freshwater divergence increased by $0.34 \mathrm{~Sv}$ between 1974 and our 8.5-yr time series (2004-12). The sign of this change is in the sense of an increase of freshwater input (e.g., increasing precipitation relative to evaporation) and a decrease in freshwater storage (e.g., increasing ocean salinity) between the Bering Strait and $26.5^{\circ} \mathrm{N}$.

We can estimate the likely size of the contributions to the freshwater divergence variability at $26.5^{\circ} \mathrm{N}$; namely, changes in salinity north of $26.5^{\circ} \mathrm{N}$ that will be observed at $26.5^{\circ} \mathrm{N}$ and changes in freshwater input, such as evaporation minus precipitation $(E-P)$. We access these contributions by examining the changes in oceanic salinity rather than integrating $E-P$, which has large uncertainties associated with it. Using repeat hydrography data Atkinson et al. (2012) identify an increase in salinity at $24.5^{\circ} \mathrm{N}$ between 1998 and 2010 with a top-tobottom average not larger than 0.005 . We quantify the contribution that this change in salinity would have to the change in freshwater divergence $\Delta F_{d}$ as follows:

$$
\Delta F_{d}=\frac{\Delta s V}{t \bar{s}}
$$

where change in salinity $\Delta s=0.005$, volume of change $V$ is the volume of subtropics north of $26.5^{\circ} \mathrm{N}$ [width of Atlantic $(4000 \mathrm{~km}) \times$ depth $(4000 \mathrm{~m}) \times$ latitudinal extent of subtropical gyre north of $\left.26.5^{\circ} \mathrm{N}\left(10^{\circ}\right)\right]=1.8 \times$ $10^{16} \mathrm{~m}^{3}$, time $t=10 \mathrm{yr}=3.2 \times 10^{8}$ seconds, and sectionaverage salinity $\bar{s}=35.17$. Thus, the change in freshwater divergence associated with this change in salinity is $0.008 \mathrm{~Sv}$. This is an order of magnitude smaller than any of the components of the freshwater divergence (horizontal, overturning, throughflow) or the uncertainty associated with them. It is also smaller than the difference between the historical estimates and the average of this time series of around $0.3 \mathrm{~Sv}$. The implication is that the changes in freshwater divergence (if they are a long-term change rather than an aliased signal) are mostly associated with volume flux divergence rather than changes in salinity, consistent with an intensification of the oceanic hydrological cycle.

Acknowledgments. Elaine McDonagh, Brian King, Harry Bryden, and Peggy Courtois were funded by NERC via the RAPID-WATCH MONACO Grant NE/ G007764/1. Zoltan Szuts was supported by an Abrupt Climate Change Research fellowship from the Comer Science and Education Foundation and by the Max
Planck Society for the Advancement of Science. Molly Baringer is supported by the NOAA/Atlantic Oceanographic and Meteorological Laboratory (AOML). Chris Atkinson was supported by a NERC Ph.D. studentship. Gerard McCarthy is supported by the NERC RAPIDWATCH program and the European Commission in the 7th Framework Programme for Research through the NACLIM project (Grant Agreement 308299). Stuart Cunningham is supported by the Scottish Funding Council through the Marine Alliance for Science and Technology Scotland program and NACLIM. The $26.5^{\circ} \mathrm{N}$ array is a collaborative effort supported through the NERC RAPID-WATCH program, the NSF meridional overturning circulation heat-flux array project, and the NOAA western boundary time series project. Data from the RAPID-WATCH and MOCHA projects are freely available online (www.rapid.ac.uk/ rapidmoc; www.rsmas.miami.edu/users/mocha). Florida Current transport estimates are also available online (www.aoml.noaa.gov/phod/floridacurrent). Argo data were collected and made freely available by the International Argo Project and the national programs that contribute to it (http://www.argo.ucsd.edu; http:// www.jcommops.org/argo). Hydrographic data were made available through GO-SHIP (www.go-ship.org) and preceding programs at the CLIVAR and carbon hydrographic data office (CCHDO; http://cchdo.ucsd.edu). We thank the many investigators that contribute to these programs.

\section{APPENDIX}

\section{Uncertainty of Continuous Salinity Flux and Freshwater Divergence}

\section{a. Elements of the uncertainty estimate}

We calculate the uncertainty of each 10-day estimate of salinity flux (and freshwater divergence) by estimating and combining the transport-derived uncertainty $\sigma \mathrm{ST}_{T}$ and salinity-derived uncertainty $\sigma \mathrm{ST}_{S}$ for each element of the calculation.

The transport-derived uncertainty $\sigma \mathrm{ST}_{T}$ is the product of the transport uncertainty $\sigma T_{\text {region }}$ and the salinity anomaly $\langle S\rangle_{\text {region }}-\langle S\rangle_{\text {average }}$. The salinity anomaly is with reference to the section-average salinity $\langle S\rangle_{\text {average }}$ $(=35.17)$, since any uncertainty in the velocity field is offset by a transport at the section-average salinity. In the western boundary wedge and for Ekman we assume that the transport uncertainty is $10 \%$ of the total relevant transport. To indicate the sensitivity to this assumption we note that halving the transport uncertainty in these subregions to $5 \%$ decreases the total freshwater uncertainty (calculated in section $\mathrm{i}$ of the appendix) 
TABLE A1. Estimates of salinity and transport uncertainty. Section-average salinity is 35.170 . When combined in quadrature each 10-day estimate of freshwater flux has an uncertainty of $0.05 \mathrm{~Sv}$. If we assume that there are 12 independent estimates in the year then the uncertainty on the annual average freshwater flux is $0.05 \mathrm{~Sv} /(12)^{1 / 2}=0.02 \mathrm{~Sv}$.

\begin{tabular}{|c|c|c|c|c|c|c|c|}
\hline & $\begin{array}{l}\sigma T_{\text {region. }} \\
\quad(\mathrm{Sv})\end{array}$ & $\begin{array}{c}\langle S\rangle_{\text {region }}-\langle S\rangle_{\text {average }} \\
(\mathrm{psu})\end{array}$ & $\begin{array}{c}\sigma \mathrm{ST}_{T} \\
(\mathrm{~Sv} \mathrm{psu})\end{array}$ & $\begin{array}{c}\sigma S_{\text {region }} \\
\quad(\mathrm{psu})\end{array}$ & $\begin{array}{l}\langle T\rangle_{\text {region }} \\
\quad(\mathrm{Sv})\end{array}$ & $\begin{array}{c}\sigma \mathrm{ST}_{S} \\
(\mathrm{~Sv} \mathrm{psu})\end{array}$ & $\begin{array}{c}\sigma \mathrm{ST} \\
(\mathrm{Sv} \mathrm{psu})\end{array}$ \\
\hline Florida Straits & 0.99 & 1.03 & 1.0 & 0.03 & 31.58 & 0.9 & 1.4 \\
\hline Wedge & 0.75 & 0.87 & 0.7 & 0.04 & 7.50 & 0.3 & 0.7 \\
\hline Ekman & 0.35 & 1.86 & 0.7 & 0.04 & 3.50 & 0.1 & 0.7 \\
\hline Deep interior & 2.0 & 0.24 & 0.5 & 0.01 & 12.77 & 0.1 & 0.5 \\
\hline Upper interior & 0.9 & 0.42 & 0.4 & 0.01 & 23.65 & 0.2 & 0.4 \\
\hline Compensation & & & & 0.07 & 3 & 0.2 & 0.2 \\
\hline Bering Strait & 0.20 & 2.67 & 0.5 & 0.10 & 0.80 & 0.1 & 0.5 \\
\hline \multicolumn{6}{|c|}{ Total uncertainty in individual 10 -day salinity flux estimates } & \multicolumn{2}{|c|}{ 1.9 Sv psu } \\
\hline & \multicolumn{5}{|c|}{ Total uncertainty in individual 10-day freshwater divergence estimates } & \multicolumn{2}{|c|}{$0.05 \mathrm{~Sv}$} \\
\hline
\end{tabular}

insignificantly and it remains $0.05 \mathrm{~Sv}$. Doubling the transport uncertainty to $20 \%$ increases the total uncertainty from 0.05 to $0.07 \mathrm{~Sv}$.

The salinity-derived uncertainty $\sigma \mathrm{ST}_{S}$ is the product of the salinity uncertainty $\sigma S_{\text {region }}$ and the average transport $\langle T\rangle_{\text {region. Thus, the total uncertainty in each region is a }}$ combination of the transport and salinity uncertainties: $\left(\sigma T_{\text {region }}\right) \times\left(\langle S\rangle_{\text {region }}-\langle S\rangle_{\text {average }}\right)$ and $\left(\sigma S_{\text {region }}\right) \times$ $\left(\langle T\rangle_{\text {region }}\right)$ in quadrature (Table A1). The uncertainty in freshwater divergence is given by the total salinity flux uncertainty divided by the negative section-average salinity $(-35.17)$. Thus, for a freshwater flux that is accurate to two decimal places our salinity flux must be accurate to $0.3 \mathrm{~Sv}$ psu.

\section{b. Florida Straits: Uncertainty}

The daily Florida Straits transport uncertainty comes from the uncertainty in the calibration of the cable voltages with estimates from dropsonde surveys (1.4 Sv; Szuts and Meinen 2013; Meinen et al. 2010). The 0.99-Sv uncertainty in the 10-day average assumes 2 degrees of freedom in the average. Combined with the difference between the Florida Straits transport-weighted salinity (Szuts and Meinen 2013) and the section-average salinity $(36.2-35.17=1.03)$ the Florida Current transport-derived uncertainty is the largest element in the uncertainty budget for the total salinity (and freshwater) flux across $26.5^{\circ} \mathrm{N}$. The standard deviation of the salinity measured during repeat hydrographic occupations of the Florida Straits is 0.03 psu. Combining this with the mean transport of $31.58 \mathrm{~Sv}$ (Table 1 ) gives the salinity-derived uncertainty. The transport-derived and salinity-derived uncertainties are combined to give a total Florida Straits uncertainty of 1.4 Sv psu (Table A1).

\section{c. WBW: Uncertainty}

The wedge contains counterflows in the upper ocean (northward Antilles Current) and at depth, so it is not appropriate to consider the net transport; instead, we assume that the uncertainty is concentrated in the more variable upper ocean above $1000 \mathrm{~m}$. This region has a typical velocity (transport) of $0.5 \mathrm{~m} \mathrm{~s}^{-1}(7.5 \mathrm{~Sv}$ ), with an uncertainty of $10 \%$, or $0.75 \mathrm{~Sv}$. The salinity of this region has an average plus or minus standard deviation of 36.04 \pm 0.04 . We use the mean salinity to calculate the salinity anomaly relative to the interior $(36.04-35.17=0.87)$. The standard deviation of the salinity combines with the mean transport to calculate the salinity-derived uncertainty. These elements combine to give a total WBW uncertainty of $0.7 \mathrm{~Sv}$ psu (Table A1).

\section{d. Ekman: Uncertainty}

The average Ekman transport is $3.5 \mathrm{~Sv}$ northward (Table 1), with an uncertainty of $10 \%$ (or $0.35 \mathrm{~Sv}$ ). The average Ekman salinity is 37.03, giving a salinity anomaly of $37.03-35.17=1.86$. This gives a transport-derived uncertainty of $0.7 \mathrm{~Sv}$ psu. The OI gives a salinity mapping error of 0.15 psu in the uppermost cell used for the Ekman calculations. An uncertainty in salinity of $0.15 /(12)^{1 / 2}=$ $0.04 \mathrm{psu}$ is given by 12 decorrelated points along the length of the section $(6000-\mathrm{km}$ section and $500-\mathrm{km}$ decorrelation length scale). Thus, the salinity-derived uncertainty is $0.1 \mathrm{~Sv}$ psu, and the total uncertainty associated with the Ekman transport is $0.7 \mathrm{~Sv}$ psu.

\section{e. Upper interior: Uncertainty}

To calculate the uncertainty we use the mean southward transport of $23.65 \mathrm{~Sv}$ (Table 1), with an uncertainty of $0.9 \mathrm{~Sv}$ based on the comprehensive uncertainty analysis of RAPID transport estimates (McCarthy et al. 2015). The mean salinity in this subregion is 35.59 (Table A2), higher than the section-average salinity by 0.42 . The uncertainty in the salinity field comes from the OI mapping error. Using a mapping error of 0.05 and assuming that there are 12 independent points along the section gives a salinity uncertainty of $0.01 \mathrm{psu}$. This 
TABLE A2. The salinity flux (total) for each of six hydrographic repeat sections at $24.5^{\circ} \mathrm{N}$ in the interior (east of the western boundary wedge) for the (top) upper interior (shallower than $1760 \mathrm{dbar}$ ) and (bottom) deep interior (deeper than 1760 dbar). The total is split into components: overturning, horizontal, and average.

\begin{tabular}{|c|c|c|c|c|c|c|}
\hline \multicolumn{7}{|c|}{ Upper interior } \\
\hline & $\begin{array}{c}\text { Total } \\
(\text { Sv psu) }\end{array}$ & $\begin{array}{l}\text { Overturning } \\
\text { (Sv psu) }\end{array}$ & $\begin{array}{l}\text { Horizontal } \\
(\mathrm{Sv} \text { psu })\end{array}$ & $\begin{array}{l}\text { Average } \\
\text { (Sv psu) }\end{array}$ & $\begin{array}{c}\text { Transport } \\
(\mathrm{Sv})\end{array}$ & $\begin{array}{c}\text { Average salinity } \\
\text { (psu) }\end{array}$ \\
\hline 1957 & -649.3 & -18.2 & -1.9 & -629.2 & -17.7 & 35.557 \\
\hline 1981 & -787.5 & -20.6 & -1.3 & -765.6 & -21.52 & 35.576 \\
\hline 1992 & -717.3 & -19.4 & 1.6 & -699.5 & -19.66 & 35.587 \\
\hline 1998 & -981.3 & -20.0 & -0.8 & -960.6 & -26.97 & 35.609 \\
\hline 2004 & -1033.3 & -25.7 & 2.9 & -1010.5 & -28.39 & 35.593 \\
\hline 2010 & -869.9 & -18.7 & -3.1 & -848.2 & -23.83 & 35.592 \\
\hline \multicolumn{7}{|c|}{ Deep interior } \\
\hline & $\begin{array}{c}\text { Total } \\
(\mathrm{Sv} \text { psu) }\end{array}$ & $\begin{array}{l}\text { Overturning } \\
\text { (Sv psu) }\end{array}$ & $\begin{array}{l}\text { Horizontal } \\
(\text { Sv psu })\end{array}$ & $\begin{array}{l}\text { Average } \\
(\mathrm{Sv} p s u)\end{array}$ & $\begin{array}{c}\text { Transport } \\
\text { (Sv) }\end{array}$ & $\begin{array}{c}\text { Average salinity } \\
\text { (psu) }\end{array}$ \\
\hline 1957 & -668.4 & -0.3 & 0.0 & -668.2 & -19.12 & 34.937 \\
\hline 1981 & -557.1 & -0.2 & 0.1 & -557.0 & -15.95 & 34.93 \\
\hline 1992 & -588.9 & -0.4 & 0.1 & -588.6 & -16.85 & 34.93 \\
\hline 1998 & -412.7 & -0.4 & 0.1 & -412.4 & -11.81 & 34.929 \\
\hline 2004 & -367.5 & -0.4 & 0.4 & -367.4 & -10.52 & 34.929 \\
\hline 2010 & -424.0 & -0.7 & 0.2 & -423.5 & -12.13 & 34.925 \\
\hline
\end{tabular}

gives a combined uncertainty of $0.4 \mathrm{~Sv}$ psu for the upperinterior salinity flux (Table A1).

The uncertainty associated with the assumptions made in calculating the interior salinity flux is assessed using the six hydrographic repeat sections at $24.5^{\circ} \mathrm{N}$ in 1957, 1981, 1992, 1998, 2004, and 2010. The velocity fields (geostrophic interior balanced by Ekman and Florida Straits transport estimate; from Atkinson et al. 2012) are combined with the salinity data from each occupation of the hydrographic section. The freshwater flux for each of these occupations is determined by adjusting the salinity flux for each section to match the Bering Strait salinity flux (-26Svpsu) as described previously for the continuous estimate of freshwater flux. We then examine the structure of the salinity flux in the interior by decomposing the total salinity flux into an average, overturning, and horizontal salinity flux in the upper and deep ocean (Table A2). Within each subregion the velocity field as well as the salinity field is decomposed into an average, overturning, and horizontal component, as in Eqs. (5) and (6). The average salinity transport in each subregion is the product of the average transport and average salinity. The overturning salinity transport is the sum of the product of the overturning salinity and transport field. The horizontal salinity flux is the sum of the product of the residual salinity and velocity fields. For the hydrographic repeat sections, the interior is defined as starting where the water depth is $3800 \mathrm{~m}$ (depth of WB2 that marks the separation between the western boundary wedge and the interior in the RAPID array) eastward from the
Bahamian shelf. This provides the best consistency when comparing sections that occupy different tracks at the western boundary (Fig. 1).

The decomposition of the interior flow into average, horizontal, and overturning components above $1760 \mathrm{dbar}$ shows that the total salinity transport is dominated by the average flux for all years. In the upper-ocean interior both the overturning and horizontal salinity fluxes are typically one to two orders of magnitude larger than the $0.3 \mathrm{~Sv}$ psu threshold for significance, justifying the description of the upper-ocean interior flow using the Argo OI product.

\section{f. Deep interior: Uncertainty}

The average southward transport in the deep interior is 12.77 Sv (Table 1), with an uncertainty of $2.0 \mathrm{~Sv}$ based on the uncertainty analysis of RAPID transport estimates (McCarthy et al. 2015). From the repeat hydrographic sections the average salinity is 34.93 , which is lower by 0.24 compared with the section-average salinity of 35.17. The standard deviation of the salinity in this subregion is 0.01 psu. The combination of these elements contributes an uncertainty of $0.5 \mathrm{~Sv}$ psu on each 10-day estimate of the salinity flux from the deep ocean (Table A1).

We also assess the uncertainty associated with the two assumptions made in section $2 \mathrm{f}$ to calculate the salinity flux in the deep interior. The first assumption is that the section-average salinity at each depth is well represented by the average of the endpoint salinities. The second assumption is that we neglect the horizontal salinity fluxes in the deep ocean. 
We look at the effect of using the average of the endpoint salinities rather than the average of all interior salinities by comparing the endpoint average with the full average from the hydrographic section. The ratio of these two quantities varies from 0.9995 to 1.0005 , and thus the magnitude of the difference (max of $\sim 0.05 \%$ or $0.0005 \times 35 \mathrm{psu} \times 1 \mathrm{~Sv}=0.018 \mathrm{~Sv} \mathrm{psu}$ ) would make an insignificant difference to the freshwater flux.

The overturning salinity transport deeper than 1760 dbar ranges from -0.2 to $-0.7 \mathrm{~Sv}$ psu (Table A2, bottom), and thus we consider it significant and include it in our calculations of salinity and freshwater flux. The horizontal salinity flux is less (in magnitude) than the $0.3 \mathrm{~Sv}$ psu significance threshold in all years except 2004 when it is $0.4 \mathrm{~Sv}$ psu. We do not include this component in the salinity flux or uncertainty calculations; note that even if we add $0.4 \mathrm{~Sv}$ psu to our estimate of deep-interior salinity flux uncertainty it does not change the total uncertainty on the individual 10-day freshwater divergence estimates of $0.05 \mathrm{~Sv}$. Based on these calculations we include the overturning salinity flux in the deep interior. In addition, the assumption that in the deep ocean the overturning salinity field is well determined by the average of the endpoint salinities has an insignificant uncertainty associated with it. Similarly the horizontal salinity flux in this subregion is insignificant and can be neglected without adding to the uncertainty.

\section{g. Barotropic compensation: Uncertainty}

In satisfying the net salinity flux constraint we apply a uniform velocity at the section-average salinity. Here we quantify the uncertainty in the assumption that the offset occurs at the section-average salinity; the compensation must have no vertical structure (i.e., act on the column average salinity) but it might have horizontal structure. Thus, this element in Table A1 has only one component due to salinity uncertainty. The representative transport of the compensation is $3 \mathrm{~Sv}$ (the typical size of the compensation added as part of the RAPID calculations plus the freshwater flux calculated here). The standard deviation of the column average salinity is 0.07 , which gives a total uncertainty of $0.2 \mathrm{~Sv}$ psu.

\section{h. Bering Strait constraint: Uncertainty}

The salinity flux across $26.5^{\circ} \mathrm{N}$ is constrained to equal the mean salinity flux through the Bering Strait. Here we quantify the uncertainty in the mean salinity flux through the Bering Strait, including the component of uncertainty introduced by the seasonal cycle observed to exist at the Bering Strait (Woodgate et al. 2005). The mean volume flux at the Bering Strait is $0.8 \mathrm{~Sv}$ at a mean salinity of 32.5 , which is 2.67 lower than the sectionaverage salinity of 35.17 . We assign a salinity uncertainty of 0.1 psu (Woodgate et al. 2005) and a volume uncertainty of $0.2 \mathrm{~Sv}$, which is half the peak-to-peak seasonal variability (Table A1).

In summary we note two points about the uncertainty associated with the Bering Strait. First, the effect of the uncertainty at the Bering Strait on uncertainty in freshwater divergence is small; only 2 of the 7 components are smaller. Second, variability in the Bering Strait flux significantly affects only the throughflow component of the decomposed freshwater flux. Thus, all of the uncertainty or variability in the Bering Strait salinity flux constraint contributes only to uncertainty in the throughflow component at $26.5^{\circ} \mathrm{N}$.

\section{i. Total uncertainty}

Combining the component estimates of the uncertainty in quadrature gives a total uncertainty in each 10-day estimate of the salinity flux of $1.9 \mathrm{~Sv}$ psu, which equates to $0.05 \mathrm{~Sv}$ in freshwater divergence (Table A1). Assuming that there are 12 independent estimates in the year, gives an uncertainty on the annual mean of $0.02 \mathrm{~Sv}$.

\section{REFERENCES}

Atkinson, C. P., H. L. Bryden, S. A. Cunningham, and B. A. King, 2012: Atlantic transport variability at $25^{\circ} \mathrm{N}$ in six hydrographic sections. Ocean Sci., 8, 497-523, doi:10.5194/os-8-497-2012.

Baringer, M. O., and J. C. Larsen, 2001: Sixteen years of Florida Current transport at $27^{\circ}$ N. Geophys. Res. Lett., 28, 3179-3182, doi:10.1029/2001GL013246.

Brooks, I. H., and P. P. Niiler, 1977: Energetics of the Florida Current. J. Mar. Res., 35, 163-191.

Bryden, H. L., B. A. King, and G. D. McCarthy, 2011: South Atlantic overturning circulation at $24^{\circ}$ S. J. Mar. Res., 69, 38-55, doi:10.1357/002224011798147633.

Curry, R., 2002: Hydrobase2: A database of hydrographic profiles and tools for climatological analysis. Woods Hole Oceanographic Institute, accessed 15 February 2011. [Available online at http://www.whoi.edu/science/PO/hydrobase/].

Dee, D. P., and Coauthors, 2011: The ERA-Interim reanalysis: Configuration and performance of the data assimilation system. Quart. J. Roy. Meteor. Soc., 137, 553-597, doi:10.1002/qj.828.

Dobroliubov, S. A., 1997: Freshwater transport in the North Atlantic Ocean: Intercomparison of balance and direct estimates. Preprints, 22nd General Assembly on Intercomparison and Validation of the Ocean-Atmosphere Flux Field, Vienna, Austria, European Geophysical Society, OA8.

Durack, P. J., and S. E. Wijffels, 2010: Fifty-year trends in global ocean salinities and their relationship to broad-scale warming. J. Climate, 23, 4342-4362, doi:10.1175/2010JCLI3377.1.

Feulner, G., S. Rahmstorf, A. Levermann, and S. Volkwardt, 2013: On the origin of the surface air temperature difference between the hemispheres in Earth's present-day climate. J. Climate, 26, 7136-7150, doi:10.1175/JCLI-D-12-00636.1.

Hall, M. M., and H. L. Bryden, 1982: Direct estimates and mechanisms of ocean heat transport. Deep-Sea Res., 29A, 339-359, doi:10.1016/0198-0149(82)90099-1.

Johns, W. E., and Coauthors, 2011: Continuous, array-based estimates of Atlantic Ocean heat transport at $26.5^{\circ} \mathrm{N}$. J. Climate, 24, 2429-2449, doi:10.1175/2010JCLI3997.1. 
Kalnay, E., and Coauthors, 1996: The NCEP/NCAR 40-Year Reanalysis Project. Bull. Amer. Meteor. Soc., 77, 437-471, doi:10.1175/ 1520-0477(1996)077<0437:TNYRP>2.0.CO;2.

King, B. A., 2012: RRS Discovery Cruise 346, 05 Jan-19 Feb 2010. The 2010 transatlantic hydrography section at $24.5^{\circ} \mathrm{N}$. National Oceanography Centre Rep. 16, 177 pp.

Kistler, R., and Coauthors, 2001: The NCEP-NCAR 50-Year Reanalysis: Monthly means CD-ROM and documentation. Bull. Amer. Meteor. Soc., 82, 247-267, doi:10.1175/ 1520-0477(2001)082<0247:TNNYRM > 2.3.CO;2.

Lavin, A. M., H. L. Bryden, and G. Parrilla, 2003: Mechanisms of heat, freshwater, oxygen and nutrient transports and budgets at $24.5^{\circ} \mathrm{N}$ in the subtropical North Atlantic. Deep-Sea Res. I, 50, 1099-1128, doi:10.1016/S0967-0637(03)00095-5.

Macdonald, A. M., 1998: The global ocean circulation: A hydrographic estimate and regional analysis. Prog. Oceanogr., 41, 281-382, doi:10.1016/S0079-6611(98)00020-2.

Marsh, R., W. Hazeleger, A. Yool, and E. J. Rohling, 2007: Stability of the thermohaline circulation under millennial $\mathrm{CO}_{2}$ forcing and two alternative controls on Atlantic salinity. Geophys. Res. Lett., 34, L03605, doi:10.1029/ 2006 GL027815.

McCarthy, G., and Coauthors, 2015: Measuring the Atlantic meridional overturning circulation at $26^{\circ}$ N. Prog. Oceanogr., 130, 91-111, doi:10.1016/j.pocean.2014.10.006.

McDougall, T. J., and P. M. Barker, 2011: Getting started with TEOS-10 and the Gibbs seawater (GSW) oceanographic toolbox, Intergovernmental Oceanographic Commission Rep., 28 pp. [Available online at http://www.teos-10.org/ pubs/Getting_Started.pdf.]

, and Coauthors, 2010: The international thermodynamic equation of seawater-2010: Calculation and use of thermodynamic properties. Intergovernmental Oceanographic Commission Rep. 56, 196 pp. [Available online at http://www.teos-10.org/ pubs/TEOS-10_Manual.pdf.]
Meinen, C. S., M. O. Baringer, and R. F. Garcia, 2010: Florida Current transport variability: An analysis of annual and longer-period signals. Deep-Sea Res. I, 57, 835-846, doi:10.1016/j.dsr.2010.04.001.

Rhein, M., and Coauthors, 2013: Observations: Ocean. Climate Change 2013: The Physical Science Basis, T. F. Stocker et al., Eds., Cambridge University Press, 255-316. [Available online at https://www.ipcc.ch/pdf/assessment-report/ar5/wg1/WG1AR5_ Chapter03_FINAL.pdf.]

Rosón, G., A. F. Ríos, F. F. Pérez, A. Lavín, and H. L. Bryden, 2003: Carbon distribution, fluxes, and budgets in the subtropical North Atlantic Ocean $\left(24.5^{\circ} \mathrm{N}\right)$. J. Geophys. Res., 108, 3144, doi:10.1029/1999JC000047.

Schanze, J. J., R. W. Schmitt, and L. L. Yu, 2010: The global oceanic freshwater cycle: A state-of-the-art quantification. J. Mar. Res., 68, 569-595, doi:10.1357/002224010794657164.

Smeed, D. A., and Coauthors, 2014: Observed decline of the Atlantic meridional overturning circulation 2004-2012. Ocean Sci., 10, 29-38, doi:10.5194/os-10-29-2014.

Szuts, Z. B., and C. Meinen, 2013: Salinity transport in the Florida Straits. J. Atmos. Oceanic Technol., 30, 971-983, doi:10.1175/ JTECH-D-12-00133.1.

Talley, L. D., 2008: Freshwater transport estimates and the global overturning circulation: Shallow, deep and throughflow components. Prog. Oceanogr., 78, 257-303, doi:10.1016/ j.pocean.2008.05.001.

Wijffels, S., 2001: Ocean transport of fresh water. Ocean Circulation and Climate, G. Siedler et al., Eds., Academic Press, 475-488.

- R. W. Schmitt, H. L. Bryden, and A. Stigebrandt, 1992: Transport of freshwater by the oceans. J. Phys. Oceanogr., 22, 155-162, doi:10.1175/1520-0485(1992)022<0155:TOFBTO >2.0.CO;2.

Woodgate, R. A., K. Aagaard, and T. J. Weingartner, 2005: Monthly temperature, salinity, and transport variability of the Bering Strait through flow. Geophys. Res. Lett., 32, L04601, doi:10.1029/2004GL021880. 